\title{
A Coalitional Theory of Unemployment Insurance and Employment Protection ${ }^{1}$
}

\author{
Vincent Anesi ${ }^{2}$ \\ Philippe De Donder ${ }^{3}$ \\ University of Nottingham Toulouse School of Economics \\ (Department of Economics) (GREMAQ-CNRS and IDEI)
}

First version: June 2010

This version: August 2011

\footnotetext{
${ }^{1}$ We thank Gilles Saint-Paul for stimulating discussions, as well as seminar participants in Namur, Rochester and Verona. We also thank two anonymous referees for helpful comments. This paper has been written while the first author was visiting the $\mathrm{W}$. Allen Wallis Institute of Political Economy at the University of Rochester. He wishes to express his appreciation to the Institute for its hospitality. All errors remain ours.

${ }^{2}$ School of Economics, Room B18, The Sir Clive Granger Building, University of Nottingham, University Park, Nottingham, NG7 2RD, United Kingdom. Email: vincent.anesi@nottingham.ac.uk.

${ }^{3} 21$ allée de Brienne, 31000 Toulouse. France. Email: dedonder@cict.fr
} 


\begin{abstract}
This paper examines the role of coalition formation in the empirically observed negative correlation between employment protection and unemployment benefit. We study an economy composed of four groups of agents (capitalists, unemployed people, low- and high-skilled workers), each one represented by a politician. Politicians first form political parties and then compete in a winner-takes-all election by simultaneously proposing policy bundles composed of an employment protection level and an unemployment benefit. We first show that, in the absence of parties (i.e., in a citizen-candidate model), low-skilled workers are decisive and support a maximum employment protection level together with some unemployment benefit. We then obtain that, under some conditions, allowing for party formation results in all policy equilibria belonging to the Pareto set of the coalition formed by high-skilled workers together with unemployed people. Policies in this Pareto set exhibit a negative correlation between employment protection and unemployment benefit.
\end{abstract}

JEL Codes: D72, J65, J68

Keywords: bidimensional voting, party competition, citizen-candidate, coalition formation, labor market rigidities 


\section{Introduction}

In most countries, labor markets institutions such as employment protection, unemployment benefits and minimum wage legislations prevent private parties from freely setting prices or quantities, creating rigidities. These rigidities may be at least in part socially efficient in a second-best sense. For instance, in a world where workers could be hired and fired at a hat's drop and at no cost for the employer, workers would have little incentive to acquire firm-specific skills. Employment protection could then provide incentives for workers to increase their productivity. Similarly, unemployment benefits provide insurance for risk-averse workers affected by random employability shocks.

Making the point that some rigidities may be optimal (see Blanchard and Tirole, 2007, among others) of course does not mean that the current level of rigidities is the optimal one, or that it is determined by a social planner maximizing some measure of welfare. As for the first point, many economists blame rigidities for high (long term) unemployment, especially in Europe, and have been advocating for a long time making the labor market more flexible (see for instance OECD Jobs Study, 1995). Despite these recommendations, many governments have failed to successfully implement such plans (see Section 5.1 in Boeri et al., 2006, or SaintPaul, 1996). Part of the literature has then taken a turn towards political economy explanations of both the emergence of labor market institutions and the resistance against moves towards more flexibility.

The same type of approach has been adopted by several papers studying the political economy of labor market institutions. These papers have in common that they adopt an insider-outsider view of the labor market, pitting currently employed workers against currently unemployed agents, and that they build a unidimensional model which focuses on a single institution, either unemployment benefits (UB thereafter, see Wright(1986), Persson and Tabellini (2000), Pallage and Zimmermann (2001)) or the employment protection level (EPL from now on, see Saint-Paul (1999, 2000, 2002)). ${ }^{1}$ Several papers try to understand the emergence and/or continuation of two types of equilibria, an "American" (or "Anglo-saxon") one with low UB or low EPL, and a "continental European" one with large UB or EPL. They differ in the economic model adopted (they build upon the seminal paper by Wright (1986) or rather use some version of a matching or a costly search model), the political economy equilibrium (direct majority voting or the maximization of the utility of some class of agents) and the reason why the "American" and "continental European" equilibria differ. Koeniger and Vindigni (2003) stress the importance of product market regulation and the way it affects the demand for EPL. Both Hassler et al. (2005) and

\footnotetext{
${ }^{1}$ Boeri and Burda (2003) study how the (exogenous) EPL level affects the political support for rigid wages versus individualized Nash bargaining.
} 
Belot (2007) resort to variations in the costs and benefits of mobility. Hassler et al. (1999) build on Wright (1986) by adding the possibility to save and borrow as a self insurance mechanism against the loss of one's job and show how it affects the equilibrium UB level. Vindigni (2008) studies the impact of dynamic idiosyncratic uncertainty on the political support for EPL. Brügemann (2006) shows that whether EPL creates its own political support depends on whether separation between firms and workers are voluntary or not. Cahuc and Postel-Vinay (2002) build a political economy model whose objective is to explain the emergence of both EPL and temporary jobs in many European countries. Finally, Brügemann (2003) studies whether international economic integration is likely to affect the cross-country variation in EPL.

Focusing on a single institution (UB or EPL) at a time is an interesting first step, but does not allow to explain an important stylized fact documented by Buti, Pench and Sestito (1998), Boeri et al. (2006) and Chung and Jeong (2008): namely, that there exists a negative correlation across OECD countries between both dimensions, with countries exhibiting low employment protection and large insurance programs, and vice versa. The objective of our paper is to understand the role of coalition formation in explaining this negative correlation between employment protection and insurance.

Addressing this question requires building a voting model with endogenous political coalitions and a bidimensional policy space. It is our opinion that a meaningful depiction of labor markets must allow voters to differ in more than one dimension. We wish to distinguish three ways in which voters may differ from each other. First, they differ in their main source of income (workers vs capitalists). Second, at any point in time, workers may be employed or not (the insider-outsider conflict). Third, employed workers may differ in their ability. Given that agents differ on more than one dimension, the decision making process should put a lot of emphasis on the political alliances that these different groups of voters may strike with each others. This in turn means that we wish to depart from the usual two party approach adopted in a large part of the political economy literature. It seems to us very difficult to state ex ante which party represents which voters. Saint-Paul (1996, p.281) discusses this point at length, criticizing the idea that left wing parties represent "labor" while right-wing parties are biased against it. We consider it much more fruitful to allow voters to be represented by politicians who decide which alliances to strike with each other and which political parties to form. In such a framework, both the number of parties and their constituents are endogenous at equilibrium.

We adapt the economic model from Pagano and Volpin (2005) to fit our purpose. The economy is populated with capitalists and workers. A subset of workers are hired in the initial stage and can invest in firm-specific human capital in order to increase their productivity. They differ in their ability to become more productive, which can be either low or high. Productivity is observable by all but non contractible. 
The firm then tries to fire low-productivity workers (those who have not invested or for whom the investment has not paid off) in order to replace them with lower-paid currently unemployed workers. This attempt to fire people may be voided in court with a probability that increases with the degree of employment protection. The public policy consists of both this EPL and a tax which finances an UB. The vote is taken at an interim stage, when workers have already invested in human capital but before the investment has proved fruitful or not. We assume that no group forms a majority by itself, that low-skilled workers form the largest group, and that they form a majority when they join forces with either the high-skilled workers or the unemployed.

Our modelling of political competition is based on Levy (2004). Her approach is particularly well suited to our problem, since (i) unlike in the traditional Downsian model, equilibria in pure strategies do exist with multidimensional policy spaces and (ii) both the number and the constituency of political parties are endogenous. At the voting stage, there are four groups of citizens (capitalists, unemployed agents, low- and high-skilled workers), each represented by one politician. These politicians first form coalitions (parties) and then compete in a winner-takes-all election by simultaneously proposing policy bundles composed of an EPL and an UB. The incentive to form a party resides in the ability to enlarge the set of credible proposals: while individual politicians are restricted to proposing their most-favored policy (no other proposal would be considered as credible by voters), parties can propose any policy that is in the Pareto set of their constituents (i.e., any policy that may be the result of efficient bargaining between party members is deemed credible by voters). The equilibrium of this game is then composed of a partition of politicians into parties and of the vector of policies proposed by these parties. $^{2}$

Our results run as follows. Both capitalists and unemployed agents prefer no EPL while workers (both low- and high-skilled) prefer maximum EPL. In terms of UB, capitalists want none while unemployed agents would like a very large one. Employed workers are in between, with low skill workers preferring a larger benefit than high skill workers. Preferences of unemployed and (especially high-skilled) workers are thus very much opposed. As a result, the Pareto set of these two groups trades-off a lower protection level against a larger employment benefit - i.e., it exhibits a negative correlation between those two dimensions.

In the absence of political parties (i.e., when each group is represented by a citizen-candidate restricted to either running with his most-favored policy or not

\footnotetext{
${ }^{2}$ There are few models where the number of parties is endogenous. Two recent examples are Iaryczower and Mattozzi (forthcoming) and Eguia (forthcoming), although the latter focuses on parties of parliamentary origin (i.e., voting blocks among legislators) rather than arising as the result of interactions between candidates and voters in elections).
} 
running in the elections), the unique equilibrium policy consists of the most-preferred package of the low-skilled workers: a very large EPL together with a moderate UB. We then show that allowing for the formation of political parties drastically changes the set of equilibrium policies. ${ }^{3}$ We obtain that, provided that high-ability workers and unemployed agents can agree on some policy that both strictly prefer to the most-favored policy of the low-ability workers, there exists an equilibrium where high-ability workers and unemployed coalesce in a party and win by proposing a policy with some positive UB and EPL. We then state two other conditions that, if satisfied, jointly insure that the only policies that are proposed in all equilibria belong to the Pareto set of the coalition made of high-ability workers together with unemployed agents. We claim that these conditions are empirically relevant, so that the predictions of the model accommodate the empirically found, negative correlation between job protection and insurance. In particular, our model is consistent with the emergence of policies that contradict the intuition from standard median voter approaches. Section 5 offers a discussion of these results, including the presentation of a real world example fitting the results of our model.

Before embarking on the description and solving of the model, let us briefly review the related literature. Our paper sits at the intersection between two different literatures: the theoretical literature on the political economy of labor market institutions described above and the one devoted to coalition formation and its impact on the determination of public policies. The latter has been surveyed by Dhillon (2005). She distinguishes models of pre-election coalition formation (such as the model we develop here) from post election coalition (or government) formation. Pre-election coalition formation models differ in the main motivations for parties to form (mainly, the sharing of the costs of running for elections, the enlargement of the set of credible promises -as in our paper-, and the coordination of voters decisions), the predictions on the size and number of parties, the models and the equilibrium concepts employed. All papers surveyed by Dhillon (2005) assume a generic policy space, either uni- or bi-dimensional, with Euclidean preferences. Other papers have applied the modelling and solution concepts developed in these contributions to specific economic environments. Variations of the coalition formation approach that we use in this paper have been applied to the study of the public provision of education by Levy (2005), to diversity and redistribution by Fernandez and Levy (2008), to environmental policies by Anesi and De Donder (2011), and to minority ideological positions by Anesi and De Donder (2009).

The two papers closest to ours are the only papers, to the best of our knowledge,

\footnotetext{
${ }^{3}$ As observed by a referee, the assumption that decisions regarding the two policy dimensions are taken simultaneously is also crucial, since the equilibrium policy bundle would remain the same if coalitions chose the two dimensions separately - see Levy (2004).
} 
to address the joint political determination of two policies affecting the labor market. Pagano and Volpin (2005) analyze the political determinants of investor and employment protection. We have simplified the part of their model that deals with the capital financing of the firm while we have introduced an UB. Observe that, in our model, the UB is driven by two competing logics (see saint-Paul (1996), p.274): an "insurance logic" (since the benefit provides income in case workers are fired) and a "wage formation logic" (the UB is the outside option of workers - increasing their outside option also increases the competitive wage paid by the firm). We differ totally from Pagano and Volpin (2005) in the setting of the political choice mechanism, since they adopt a probabilistic voting setting with two parties and obtain results that crucially depend (as always within the probabilistic voting approach) on assumptions regarding the distribution of ideological bias among the different categories of voters.

The other close paper is Boeri et al. (2011), who also analyze political equilibria in a model of voting over UB and EPL. In their paper, the negative correlation between UB and EPL results from political mechanisms other than coalition formation. More specifically, we differ in both the economic and the political modeling. Their economic model is an extension of Wright (1986), with workers varying in their skill levels. Both EPL and UB are set up in such a way that they redistribute in favor of low-skilled workers. The modelling of the public decision making process assumes that people vote separately on the two dimensions, and a (so-called Shepsle or induced) equilibrium is such that each instrument is set at its majorityfavored level given the other instrument. Low-skilled voters are decisive in both votes and there is substitution between EPL and UB since "a higher level of unemployment insurance for the low-skills reduces the cost, in terms of consumption, of being unemployed; thus leading a low-skill insider to require a lower degree of EPL (p. 15)." Whether low-skilled voters prefer a large EPL or UB very much depends on the amount of redistribution associated to each instrument. The authors show that "more earning inequality or a more progressive UB system involve more crossskill redistribution (...) thereby making unemployment benefits more appealing to low skill types (p.15)." The driving force for the negative relationship between UB and EPL in our model is different and comes from the fact that the Pareto set for high-skilled workers and unemployed exhibits such a relationship, with unemployed preferring a large UB and a small EPL while (high-skilled) employed have opposite preferences. 


\section{The Economic Environment}

\subsection{Basic Setting}

We consider an economy populated by a continuum of citizens of measure $1+\kappa$, $\kappa \in(0,1)$, which is partitioned into two economic classes: workers and capitalists. Workers own labor and no capital; capitalists own capital, but no labor. The measure of workers is one, so that the measure of capitalists is $\kappa$.

There are three goods in the economy: labor, capital, and a consumption good (the numeraire) produced by a single firm using labor and capital as inputs. Its Leontieff production technology exhibits a labor-capital ratio equal to $\tilde{\ell}$. All workers have the same labor endowment, normalized to 1, that they rent to the firm in exchange of a wage. Each capitalist has the same capital endowment, $k$, which is offered to the firm in exchange for a share in its ownership. Capitalists then share equally the profit (revenue minus wage bill) of the firm.

The total stock of capital is $\kappa k$ so that the firm initially hires a mass $\ell \equiv \kappa k \tilde{\ell}$ of workers in exchange of a promise of a wage $w_{I}$ (where the subscript $I$ stands for initial). We assume that $\ell<1$ so that there is some unemployment in the economy. Workers hired at this stage can make a costly effort in order to improve their productivity (such as investing in firm-specific human capital for instance). If they choose not to make this effort, their productivity is $y$. If they choose to make the effort, they incur a disutility cost $\gamma>0$ but have a probability $x_{i}$ of increasing their productivity to $y+\Delta$ (if the effort fails to prove fruitful, their productivity remains $y)$. There are two groups of workers differing in their ability to transform effort into higher productivity: $0<x_{L}<x_{H}<1$. The proportion of high-ability workers is denoted by $\lambda$, with a majority of low-ability people among workers $(\lambda \in(0,1 / 2)){ }^{4}$ Individual productivity is observable, but not contractible. ${ }^{5}$

After having observed individual productivities, the firm may try to fire some workers in order to replace them with cheaper unemployed individuals, who are offered a wage $w_{R}$ (where $R$ stands for restructuring). However, every attempt to lay off a worker can be voided by a court with probability $\pi(\mu) \in[0,1)$, where $\pi^{\prime}>0$, $\pi(0)=0$ and $\pi(1)<1 .^{6}$ We assume that it is too late at this stage for unemployed

\footnotetext{
${ }^{4}$ Saint-Paul (1996) reckons that "unskilled and semi-skilled workers (...), including workers without a college degree, make up more than $70 \%$ of the workforce in most European countries."(p.275)

${ }^{5}$ The noncontractibility of individual productivity may be viewed as a characteristic of the production technology. We refer the reader to Pagano et al. (2005, foonote 10) for further justifications of this assumption.

${ }^{6}$ The OECD measures employment protection as the strictness of procedures and costs involved in dismissing individual workers, including dimensions such as severance payments, administrative
} 
people joining the firm to invest in specific human capital, so that their productivity is $y$.

At the end of the game, payoffs are distributed according to the status of individuals at that time. The individuals who are unemployed at the end of the game receive an unemployment benefit, denoted by $\beta$. The wage paid to people working in the firm depends upon their seniority: people employed since the initial stage are paid $w_{I}$ (irrespective of their -non contractible- productivity) while people hired at the restructuring stage are paid $w_{R}$. Capitalists share equally the profit of the firm. Everybody pays the same lump sum tax $\tau \geq 0$, whose proceeds finance the unemployment benefit. The unemployment benefit $\beta$ is obtained using the government budget constraint

$$
(1-\ell) \beta=\tau(1+\kappa) .
$$

The tax $\tau$ forms the first component of the public policy. The second component is the degree of employment protection, $\mu \in[0,1]$. Public policy is decided, by majority voting, after the workers hired at the initial stage have invested in specific human capital, but before the result of this investment is observed (by workers and the firm). Observe that the unemployment level $1-\ell$ does not depend on the unemployment benefit $\beta$ nor on the job protection policy $\mu$ in our model.

We now summarize the timing of the game:

Stage 1 (Initial hiring) Capitalists invest all their capital in the firm. The firm hires a measure $\ell \equiv \kappa k \tilde{\ell}<1$ of workers in exchange of the promise of a wage $w_{I}$.

Stage 2 (Workers' investment) Employed workers decide whether to invest in firm-specific human capital.

Stage 3 (Voting) A government is democratically elected to implement a policy vector $(\tau, \mu)$, with the unemployment benefit $\beta$ determined by the budget constraint (1).

Stage 4 (Restructuring) Employed workers and the firm learn about employees' individual productivities. The firm may try to replace some of them with currently unemployed agents in exchange of a wage $w_{R}$. However, every attempt to lay off a worker can be voided by a court with probability $\pi(\mu) \in(0,1)$.

and procedural costs and advance notices to be served. The crucial feature of EP for our model is that it reduces the employment inflows/unemployment outflows, decreasing the probability that a currently employed worker loses her job to a currently unemployed. The assumption (introduced by Pagano et al. (2005)) that the lay off attempt is voided by a court with a probability increasing in the EPL $\mu$ is a straightforward (if not totally realistic) way to capture this feature. 
Stage 5 (Production and consumption) Output is produced, capitalists receive the firm's profit, employed workers are paid their wage $\left(w_{I}\right.$ or $w_{R}$ depending on their seniority), and unemployed workers obtain the unemployment benefit. All pay the lump sum tax $\tau$.

All agents care only for the amount of consumption good consumed (they derive no benefit from leisure and so no disutility from working) and use their entire aftertax income to purchase that good. They all have the same preferences over private consumption, which are represented by a von-Neumann-Morgenstern utility function $U: \mathbb{R}_{+} \rightarrow \mathbb{R}$, with $U(0)=0, U^{\prime}>0, U^{\prime \prime}<0$, and $\lim _{c \rightarrow 0} U^{\prime}(c)=\infty$.

\subsection{Wage setting}

The firm is a monopsonist on the market for labor. In a frictionless economy, the firm would offer the smallest wage that is acceptable to the workers (the competitive wage). We rather assume that workers are able to obtain a gross mark-up $\rho \geq 1$ on the competitive wage. ${ }^{7}$ We solve the game backward, starting with the restructuring stage (since there is no decision to be taken at the last stage). Agents have no disutility from working, so that the competitive wage for newly hired workers is equal to their outside option, the unemployment benefit $\beta$. The wage offered to new workers at this stage is then

$$
w_{R}=\rho \beta=\rho \tau \frac{1+\kappa}{1-\ell}
$$

where the second equality is obtained from the budget constraint (1). The after-tax income of these workers is

$$
\rho \beta-\tau=\rho \tau \frac{1+\kappa}{1-\ell}-\tau
$$

The before-tax income of unemployed agents is the unemployment benefit $\beta=\tau \frac{1+\kappa}{1-\ell}$ with the corresponding after-tax income $\beta-\tau=\tau \frac{\ell+\kappa}{1-\ell}$. Observe that a consequence of (2) is that the firm has an incentive to fire low productivity workers (in order to replace them with unemployed agents) as soon as the competitive wage in the first stage is larger than the unemployment benefit (i.e., as soon as $w_{I}>\rho \beta$ ).

\footnotetext{
${ }^{7}$ This mark-up may arise for various unmodelled reasons, such as frictions in a search model,
} bilateral bargaining between firm and worker, or existence of a trade-union as in Lee and Roemer (2005). Without such a mark-up, individuals would be indifferent between working and being unemployed, and thus indifferent as to the EPL. 
The rest of the paper will be devoted to the study of the third, majority voting, stage. In order to solve that stage, we need to construct individuals' preferences for the policy options $\tau$ and $\mu$. This in turn requires to solve for workers' decision to invest or not in human capital, and for the wage $w_{I}$ that is offered to them in the first stage. To do this, we assume for the moment that a policy pair $(\tau, \mu)$ has been chosen and we move to the second stage, where voters choose whether to invest or not in human capital.

Making the effort of investing in human capital has a sure cost, $\gamma$, and an uncertain return. This return takes the form not of a higher wage (because productivity is not contractible), but rather of a larger probability of remaining employed. Hence, for workers to choose to make this effort, it must be the case that (i) their wage if they remain employed is larger than the employment benefit they would receive if fired, and (ii) the firm tries to fire workers of low productivity, and only them (if the firm's decision to fire did not depend on the productivity of the worker, then no worker would have an incentive to make the effort, and thus no one would exhibit a high productivity at equilibrium).

We then look at the case where the firm's owners (the capitalists) benefit when the workers of type $i$ choose to make the effort of trying to be more productive. This in turn means that the firm tries to fire all workers with low productivity (and only them). Anticipating this, workers of type $i$ make this effort only if the expected payoff from making the effort is larger than the expected payoff if they do not make the effort: ${ }^{8}$

$$
\begin{aligned}
{\left[x_{i}+\left(1-x_{i}\right) \pi(\mu)\right] U\left(w_{I}-\tau\right) } & +\left(1-x_{i}\right)[1-\pi(\mu)] U(\beta-\tau)-\gamma \\
& \geq \pi(\mu) U\left(w_{I}-\tau\right)+[1-\pi(\mu)] U(\beta-\tau) .
\end{aligned}
$$

The payoff when investing (the left-hand side of (3)) increases with ability (because the investment has a larger chance to succeed) while the payoff when not investing (the right-hand side of (3)) does not depend on ability, so that if the constraint is satisfied for low ability workers, it is also satisfied for high ability workers. We show in Appendix 1 that a large enough value of $\Delta$ guarantees both that the capitalists' payoff is strictly positive at equilibrium, and that the firm's profit is larger when all workers are induced to invest in human capital. The intuition is straightforward, since a large value of $\Delta$ makes the investment very productive for the firm (and hence its owners).

\footnotetext{
${ }^{8}$ Throughout the paper, we make use of the Law of Large Numbers (since there is a continuum of citizens) so that the measure of workers who (un)successfully invest in human capital can be computed with certainty. We refer the reader to Mukoyama and Şahin (2005) for a characterization of the optimal wage contract in settings where the current (hidden) action of an worker has a persistent effect on the future outcome.
} 
We then solve for $w_{I}$ in (3) and we obtain the competitive wage $w_{c}$ - the minimum wage offered in the initial stage that would induce all employed workers to invest in human capital — as

$$
w_{c}=\tau+U^{-1}\left(U(\beta-\tau)+\frac{\gamma}{[1-\pi(\mu)] x_{L}}\right)>\beta .
$$

Let us now move to the first stage and to the setting of the wage $w_{I}$. The firm's owners (the capitalists) set the wage at a level corresponding to the gross mark-up $\rho$ over the wage level (4): a worker hired in the initial stage and keeping his job until the end of the game will receive a wage of $w_{I}=\rho w_{c}$. His final after-tax income is then $\rho w_{c}-\tau$. Finally, we assume that individuals have a larger expected payoff if they get hired in the initial stage than if they were to remain unemployed at that stage. We show in the next section that this assumption is satisfied provided that the effort cost $\gamma$ is low enough. ${ }^{9}$

We are now in a position to study the preferences of agents at the voting stage.

\section{$2.3 \quad$ Voter preferences}

Policy preferences in the third stage depend upon voters' type $\theta$. Voters can be $i$-ability employed workers $\left(\theta=e_{i}, i \in\{L, H\}\right)$, unemployed $(\theta=u)$, or capitalists $(\theta=c)$. Recall that, at the voting stage, all currently employed agents have already incurred the cost associated to their effort to be more productive, but are yet to know whether this effort will prove fruitful. Workers as well as currently unemployed individuals form expectations as to their status in the final stage of the game, and thus as to their final payoff.

Let $p:[0,1] \times\left\{e_{L}, e_{H}, u\right\} \rightarrow(0,1)$ be the probability for a voter of type $\theta \in\left\{e_{L}, e_{H}, u\right\}$ to be employed at the production phase when the EPL is $\mu$. This probability is given by

$$
p(\mu, \theta) \equiv \begin{cases}x_{i}+\left(1-x_{i}\right) \pi(\mu) & \text { if } \theta=e_{i}, i \in\{L, H\} \\ \frac{(1-x)[1-\pi(\mu)] \ell}{1-\ell} & \text { if } \theta=u,\end{cases}
$$

where $x \equiv \lambda x_{H}+(1-\lambda) x_{L}$ is the average proportion of high productivity workers (equal to the expected proportion by the law of large numbers). We define the policy space as $P \equiv[0, \bar{\tau}] \times[0,1]$ for some exogenous value of $\bar{\tau} .{ }^{10}$

\footnotetext{
${ }^{9}$ It is straightforward from the definitions of $w_{R}, \beta$ and $w_{I}$ that all workers and unemployed agents enjoy positive after-tax consumption at equilibrium.

${ }^{10} \mathrm{We}$ need to impose an exogenous value of $\tau$ as upperbound because tax proceeds are increasing with $\tau$ in the absence of preference for leisure.
} 
Voters' policy preferences over $P$ are then given by: ${ }^{11}$

$$
\mathbf{V}(\tau, \mu, \theta) \equiv \begin{cases}p(\mu, \theta) U\left(\rho w_{c}-\tau\right)+[1-p(\mu, \theta)] U\left(\tau \frac{\ell+\kappa}{1-\ell}\right) & \text { if } \theta \in\left\{e_{L}, e_{H}\right\} \\ p(\mu, \theta) U\left(\rho \tau \frac{1+\kappa}{1-\ell}-\tau\right)+[1-p(\mu, \theta)] U\left(\tau \frac{\ell+\kappa}{1-\ell}\right) & \text { if } \theta=u \\ U\left([y+x \Delta-\bar{w}(\mu, \beta)] \frac{\ell}{\kappa}-\tau\right) & \text { if } \theta=c\end{cases}
$$

where $\bar{w}(\mu, \beta)$ denotes the average wage paid in the production stage and is given by

$$
\bar{w}(\mu, \beta) \equiv \rho\left\{[x+(1-x) \pi(\mu)] w_{c}+(1-x)[1-\pi(\mu)] \beta\right\} .
$$

We make the following reasonable assumptions on the distribution of voters' types:

Assumption 1 (a) $\frac{1+\kappa}{2}>(1-\lambda) \ell>\max \left\{\kappa, 1-\ell+\frac{\kappa}{2}\right\}$.

(b) $1+\kappa<2 \min \{\ell, 1-\lambda \ell\}$.

(c) $\ell<\frac{x_{L}}{1-\lambda\left(x_{H}-x_{L}\right)}$.

Assumption 1(a) guarantees that the low-ability employed form the largest group but fall short of the majority. It also implies that the capitalists form an electorally small group of voters. ${ }^{12}$ Assumption 1(b) states that employed people constitute a majority of voters, as well as low-ability employed together with unemployed. Observe that we make no assumption on whether low-ability workers together with capitalists form a majority, or whether the complement made of high ability workers together with unemployed forms a majority - i.e., we allow for $\kappa+(1-\lambda) \ell \lessgtr$ $\lambda \ell+1-\ell$. As for Assumption 1(c), it guarantees that the probability for an individual unemployed (at the voting stage) of finding a job is lower than the probability for a worker employed (at the same stage) of remaining so (given that $\mathrm{s} /$ he has invested in human capital):

$$
p(\mu, \theta)>p(\mu, u) \text { for } \theta \in\left\{e_{L}, e_{H}\right\} \text { and any }(\tau, \mu) \in P .
$$

\footnotetext{
${ }^{11}$ Recall that the effort cost $\gamma$ has already been sunk at that stage, and thus does not appear in policy preferences. Also, the wage $w_{I}$ has already been set by the firm in the initial stage. As we focus on subgame perfect equilibria, we assume in the rest of the paper that $w_{c}$ is given by (4) where $\mu$ and $\tau$ are set at their equilibrium value (i.e., the value that the firm has anticipated at the initial stage of the game).

${ }^{12}$ The addition of half the capitalists to the unemployed on the right hand side of assumption 1(a) is not strictly necessary to obtain our results, but it allows to simplify the proof of Proposition 1 below. It does not imply that capitalists play no role in the election, as will be clear in section 4 .
} 
This in turn implies that the number of workers effectively fired at the restructuring stage does not exceed the number of people unemployed at that stage:

$$
(1-x)[1-\pi(\mu)] \ell \equiv p(\mu, u)(1-\ell)<p\left(\mu, e_{L}\right)(1-\ell) \leq 1-\ell .
$$

Observe that Assumption 1(c) together with $w_{c}>\beta$ implies that, at the third stage, employed workers are better off (in expectation) than unemployed workers:

$$
\mathbf{V}(\tau, \mu, \theta)>\mathbf{V}(\tau, \mu, u) \text { for } \theta \in\left\{e_{L}, e_{H}\right\} \text { and any }(\tau, \mu) \in P \text {. }
$$

This does not imply that the initial stage expected welfare is larger for employed workers than for unemployed agents, since employed workers anticipate that they will have to subtract the effort cost $\gamma$ from $\mathbf{V}(\tau, \mu, \theta)$. We then assume that $\gamma$ is low enough that individuals have a larger expected payoff in the initial stage if they get hired than if they were unemployed at that initial stage. ${ }^{13}$

Our model admittedly abstracts from important labor market phenomena, such as the presence of disutility from working, tax distortion from financing unemployment insurance, moral hazard or self-insurance. It is also static, the game described above being played only once. Introducing any of these elements or making our setting dynamic would render this model much more complex ${ }^{14}$ without affecting much the qualitative results (in terms of preferences of the four groups for EP and UB): ${ }^{15}$ preferences of voters would be less extreme than in our simple static game, with people unemployed when voting favoring some EPL (since they would hope to become insiders at some point later on, for instance) and a lower-than-maximum tax rate (for the same reason, or because of tax distortion or moral hazard phenomena), while employed workers would favor a less-than-maximum EPL. For a very large range of assumptions, we would nevertheless keep the same ranking of preferences as in the one-shot game, with for instance people employed at the time of voting preferring a larger EPL than currently unemployed. In other words, even though our simple model is geared towards a generous provision of both EP and UB, what matters for our results is the shape of preferences of the four group of voters, and these shapes are robust to the introduction of many frictions into the model.

We now introduce our definition of the political equilibrium concept.

\footnotetext{
${ }^{13}$ It is straightforward to see that agents are better off when employed in the initial stage if $\gamma=0$. By continuity this is also true for small values of $\gamma$.

${ }^{14}$ With the unemployment rate being a function of the policy decisions $\mu$ and $\tau$, for instance.

${ }^{15}$ Observe that simply repeating stages 2 to 5 would not alter our results if the labor policies chosen at stage 3 were valid only for one period (i.e., assuming that a new vote takes place after each investment decision).
} 


\section{Voting}

The main difficulty when voting over multidimensional policy spaces is the absence of Condorcet winner (i.e., of a policy bundle that is preferred by a majority of voters to any other feasible bundle). This in turn means that a classical Downsian political competition model with two parties interested only in winning elections has no equilibrium in pure strategies. We propose to adapt the model of Levy (2004), which has two extremely nice features. First, equilibria in pure strategies exist even with multidimensional policy spaces. Second, both the number and the constituency of political parties are endogenous. We present that approach in the context of our paper, but refer the reader to Levy's paper for an in-depth discussion of the basic assumptions.

Each group of voters is represented by a single politician who is a perfect representative of her group, in that her policy preferences are given by (5). ${ }^{16}$ Politicians running alone are unable to commit to any proposal differing from their ideal policy. The key assumption of Levy (2004) is, however, that politicians can credibly commit to a larger set of policies by forming political parties (or alliances): the set of policies a party can commit to is the Pareto set of its members. ${ }^{17}$ Formally, a politician is an element $\theta$ of $\Theta$ while a party is a non-empty subset $S$ of $\Theta$. A policy $(\tau, \mu) \in P$ is in the Pareto set of party $S$, denoted by $P_{S}$, if there is no other policy $\left(\tau^{\prime}, \mu^{\prime}\right)$ such that $\mathbf{V}\left(\tau^{\prime}, \mu^{\prime}, \theta\right) \geq \mathbf{V}(\tau, \mu, \theta)$ for all $\theta \in S$ and $\mathbf{V}\left(\tau^{\prime}, \mu^{\prime}, \hat{\theta}\right)>\mathbf{V}(\tau, \mu, \hat{\theta})$ for some $\hat{\theta} \in S$.

The political game we study has two stages. The first stage is one of party formation, while the second stage encompasses electoral competition, where all parties simultaneously choose a feasible policy and compete in a winner-takes-all election. We now describe how each stage takes place, beginning with the electoral competition game.

\section{Electoral Competition}

A party structure is a partition of $\Theta$ into parties. Let $\Pi$ be the set of party structures. We assume that the result of the party formation stage is some arbitrary party structure $\pi \in \Pi$. Elections then proceed as follows. Every party $S \in \pi$ chooses

\footnotetext{
${ }^{16}$ This corresponds to the citizen-candidate approach pioneered by Besley and Coate (1997) and Osborne and Slivinski (1996) and applied to lobbies and strategic campaigning by Chambers (2007).

${ }^{17}$ Models of endogenous party formation differ starkly in terms of the ability of parties to commit. At one extreme, Roemer (2005) allows parties to commit to any policy, while, at the other extreme, Gomberg et al. (2004) restrict parties to aggregate the preferences of their members.
} 
an electoral strategy (or platform), namely a policy $\left(\tau_{S}, \mu_{S}\right) \in P_{S} \cup\{\varnothing\}$, where $\varnothing$ means that the party proposes no policy (we say that it does not run). In the case where no party runs for election, every politician receives a zero payoff. If at least one party runs, we assume that voters record their preferences sincerely over any list of candidate platforms, $\mathbf{p} \equiv\left\{\left(\tau_{S}, \mu_{S}\right)\right\}_{S \in \pi}$, and that the election is by plurality rule with no abstention. ${ }^{18}$ The election outcome is then a fair lottery between the policies in

$$
W(\mathbf{p}) \equiv\left\{\left(\tau_{S}, \mu_{S}\right): S \in \arg \max _{S^{\prime} \in \pi} v_{S^{\prime}}(\mathbf{p})\right\}
$$

where $v_{S^{\prime}}(\mathbf{p})$ is party $S^{\prime}$ 's realized vote share. In line with Levy (2004), we assume that if a party is indifferent between running and not running, it chooses not to run.

Let $\psi_{\theta}(S)$ be the indicator function on $2^{\Theta}$ taking the value of 1 if $\theta \in S$ and 0 otherwise. Members of the winning party equally share an (arbitrarily small) nonpolicy benefit $b>0$ (ego-rents, perks of office...). As a consequence, the expected utility of politician $\theta$ resulting from a profile of strategies $\mathbf{p}$ is given by

$$
\mathcal{U}(\mathbf{p}, \theta) \equiv \frac{1}{|W(\mathbf{p})|} \sum_{\left(t_{S}, e_{S}\right) \in W(\mathbf{p})}\left[\mathbf{V}\left(\tau_{S}, \mu_{S}, \theta\right)+\psi_{\theta}(S) \frac{b}{|S|}\right]
$$

if there is at least one party $S \in \pi$ such that $\left(\tau_{S}, \mu_{S}\right) \neq \varnothing$, and $\mathcal{U}(\mathbf{p}, \theta)=0$ otherwise.

Given a party structure $\pi \in \Pi$, a vector of electoral strategies $\mathbf{p}=\left\{\left(\tau_{S}, \mu_{S}\right)\right\}_{S \in \pi}$ is a $\pi$-equilibrium of the electoral-competition game if no party $S \in \pi$ can make all its members better-off by deviating to another platform; that is, for all $S \in \pi$, there is no $\left(\tau_{S}^{\prime}, \mu_{S}^{\prime}\right) \in P_{S} \cup\{\varnothing\},\left(\tau_{S}^{\prime}, \mu_{S}^{\prime}\right) \neq\left(\tau_{S}, \mu_{S}\right)$, that satisfies

$$
\mathcal{U}\left(\left(\tau_{S}^{\prime}, \mu_{S}^{\prime}\right), \mathbf{p}_{-S} ; \theta\right) \geq \mathcal{U}\left(\left(\tau_{S}, \mu_{S}\right), \mathbf{p}_{-S} ; \theta\right)
$$

for all $\theta \in S$, with at least one strict inequality. In line with Levy (2004), we restrict ourselves to partisan equilibria, where voters strictly prefer their party's platform (if their party proposes one) to any other party's platform. And to avoid repeatedly having to include the relevant qualification, we leave it as understood that any reference to $\pi$-equilibria is actually to partisan $\pi$-equilibria. We also adopt the rule that if a party is indifferent between running and not running, it chooses not to run.

Let $\delta(\pi)$ be the set of $\pi$-equilibrium policy outcomes.

\footnotetext{
${ }^{18}$ Voters who are indifferent between several policies use a fair mixing device. We refer the reader to Baron et al. (forthcoming) for a model in which the electorate votes strategically by taking into account the likely governments that parties would form based on their representation and the policies they would choose.
} 


\section{Stability of Party Structures}

Up to this point, we have taken the party structure $\pi$ as given. We now turn to the party formation stage and ask whether $\pi$ is a stable party structure. First of all, note that there may exist multiple $\pi$-equilibria, and therefore multiple equilibrium outcomes $(\delta(\pi)$ may not be a singleton). Thus, $\pi$ may satisfy stability conditions for one electoral outcome but not for others. As a consequence, we will not study the stability of $\pi$ alone, but the stability of pairs $(\pi, \mathbf{p})$ where $\mathbf{p}$ is a $\pi$-equilibrium. We will refer to them as political states. Which of these should be considered as the set of equilibrium outcomes for the present model? The answer to this question depends on the stability requirements imposed on party structures.

Let $\pi$ and $\pi^{\prime}$ be two party structures. $\pi^{\prime}$ is said to be induced from $\pi$ if $\pi^{\prime}$ is formed by breaking a party in $\pi$ into two or by merging two existing parties in $\pi$ (forming a new party made up of subsets of current parties is excluded on the basis that nobody would trust a politician who is willing to betray her current partners). Now, we say that the political state $(\pi, \mathbf{p})$ is blocked by another political state $\left(\pi^{\prime}, \mathbf{p}^{\prime}\right)$ if there exists $S \in \Theta$ such that (i) $S$ can induce $\pi^{\prime}$ from $\pi$, and (ii) for every $\theta \in S$ : $\mathcal{U}\left(\mathbf{p}^{\prime}, \theta\right)>\mathcal{U}(\mathbf{p}, \theta)$. We thus define equilibrium political states as follows.

Definition 1 Let $\pi^{*} \in \Pi$, and let $\mathbf{p}^{*}$ be a profile of electoral strategies. The pair $\left(\pi^{*}, \mathbf{p}^{*}\right)$ is an equilibrium political state (EPS) if it satisfies the following conditions:

- $\mathbf{p}^{*}$ is a $\pi^{*}$-equilibrium, and

- there is no political state $(\pi, \mathbf{p})$ that blocks $\left(\pi^{*}, \mathbf{p}^{*}\right)$.

Thus, an equilibrium situation is defined as one that meets two requirements: first, the policy platforms result from the electoral competition between existing political parties; second, in every existing party, politicians have no incentive to break up their party or form a new party in order to favor different electoral outcomes.

We are now in a position to apply this political equilibrium concept to the economic environment described in the previous section. 


\section{Analysis of Equilibrium Political States}

\subsection{Policy Preferences}

This section describes voters' objectives and sources of conflict. The following lemma describes the voters' most-preferred policy bundles. ${ }^{19}$

Lemma 1 Let $(\hat{\tau}(\theta), \hat{\mu}(\theta))$ be the ideal policy of a voter of type $\theta$. Then

$$
\bar{\tau}=\hat{\tau}(u) \geq \hat{\tau}\left(e_{L}\right)>\hat{\tau}\left(e_{H}\right)>\hat{\tau}(c)=0,
$$

and, for every $i=L, H$,

$$
\hat{\mu}\left(e_{i}\right)=1>\hat{\mu}(c)=\hat{\mu}(u)=0 .
$$

The preferences in terms of protection policy $\mu$ are easy to establish. Unemployed individuals' utility is decreasing in employment protection, since it prevents them from working and earning the wage $w_{R}$ that they prefer to the unemployment benefit $\beta$. Capitalists also dislike any increase in the protection level because it increases the average wage they have to pay to workers by making it more difficult to replace low productivity workers by lower-paid unemployed. Employed workers's utility is increasing in $\mu$ (whatever their ability) because a larger protection level increases their probability to stay on the job and they are better-off employed than unemployed.

The $\operatorname{tax} \tau$ is paid by everyone. For capitalists, taxation is an especially bad deal because it increases the wage they have to offer to previously unemployed people. They thus oppose any increase in $\tau$. Unemployed people favor any increase in $\tau$ since it raises both the unemployment benefit and the wage they would receive if hired later on. The optimal tax for employed people trades off two concerns: on the one hand, they dislike paying taxes but, on the other hand, a larger tax increases the unemployment benefit they would get if fired. The optimal tax is positive since the marginal benefit of taxation grows arbitrarily large as the tax (and thus the unemployment benefit) tends towards zero. The optimal tax is higher for low-ability people because their probability of losing their job is higher than for high-ability workers.

Figure 1 represents both the four categories of voters' most-preferred policy bundles and their indifference curves in the $P$ space. Capitalists favor no taxation and no job protection. The slope of their indifference curves is everywhere negative,

\footnotetext{
${ }^{19}$ Proofs are relegated to Appendices.
} 
since they have to be compensated for a higher tax by a lower protection level. The arrow labelled " $c$ " depicts the direction of increasing utility. Unemployed workers favor no protection together with a maximum value of the tax. The slope of their indifference curves is always positive. The slope of the worker's indifference curve is negative for low values of $\tau$ (where the individual would like to increase both $\mu$ and $\tau$ ) and positive for larger values of $\tau$ (where the tax is too large given the protection level). A similar analysis applies to the low-ability employed.

Insert Figure 1 around here

The Pareto set for the group composed of high-ability workers and unemployed will play a crucial role in our results and is thus represented on Figure 1. At any interior point along this set, the indifference curves of both types are positively sloped. For the high-skilled workers, this is due to the substitutability between UB and EPL. There is no such substitutability for the unemployed, who always prefer a larger UB and a lower EPL. Under mild conditions on preferences (see condition C1 below), the Pareto set is interior to $P$ and downward sloping, ${ }^{20}$ with the unemployed's utility increasing (and high-skilled workers's utility decreasing) as one moves in the southeast direction along that curve -i.e., as one increases the UB and decreases the EPL.

\subsection{Unemployment Benefit vs. Employment Protection}

We are now in a position to determine the political equilibrium values of UB and EPL. A straightforward intuition would suggest that, as the low-ability employed form the largest group and are median voters in both dimensions of the policy space (taken separately), equilibrium policies should reflect their preferences (relatively low UB and very high EPL). This intuition is confirmed by Proposition 1 below, which characterizes the unique political equilibrium in the standard citizencandidate model without party formation -i.e., when we do not allow candidates to coalesce so that their only choice is whether to run (with their most-preferred policy bundle) or not. This means that the party formation stage is a necessary ingredient, in our model, to explain the emergence of the other equilibria empirically observed (such as those with low EPL and large UB).

Proposition 1 Let $\pi^{0} \equiv\left\{\left\{e_{H}\right\},\left\{e_{L}\right\},\{u\},\{c\}\right\}$. Then, $\delta\left(\pi^{0}\right)=\left\{\left(\hat{\tau}\left(e_{L}\right), \hat{\mu}\left(e_{L}\right)\right)\right\}$.

\footnotetext{
${ }^{20}$ Proof available upon request to the authors.
} 
With the citizen-candidate approach (corresponding to the partition of candidates labelled as $\pi^{0}$ in the statement of Proposition 1), the set of admissible policy bundles is restricted to those most-preferred by the four types of candidates. Proposition 1 follows from the fact that the most-preferred policy of low-ability workers is preferred by a majority of voters to any of the most-preferred policies of the three other types. From Assumption 1(b), the low-ability workers together with either the high-ability workers or the unemployed form a majority. We show that high-ability workers prefer $\left(\hat{\tau}\left(e_{L}\right), \hat{\mu}\left(e_{L}\right)\right)$ to $(\hat{\tau}(u), \hat{\mu}(u))$ because they dislike both the high tax and the absence of protection favored by the unemployed. Unemployed individuals prefer $\left(\hat{\tau}\left(e_{L}\right), \hat{\mu}\left(e_{L}\right)\right)$ with its positive unemployment benefit and wage to the zero unemployment benefit and wage favored by the capitalists at $(\hat{\tau}(c), \hat{\mu}(c))$, even if the former policy gives them a smaller chance of finding a job than the latter. Unemployed agents also prefer $\left(\hat{\tau}\left(e_{L}\right), \hat{\mu}\left(e_{L}\right)\right)$ to $\left(\hat{\tau}\left(e_{H}\right), \hat{\mu}\left(e_{H}\right)\right)$ because of the low tax favored by high-ability workers (both policies share the same employment protection level). Hence, the unique one-candidate $\pi^{0}$-equilibrium has the $e_{L^{-}}$-candidate running alone and implementing her ideal policy. The rest of the proof of the Proposition shows that low-ability workers are powerful enough that there is no $\pi^{0}$-equilibrium with more than one candidate running for office.

Proposition 1 implies that, in the absence of parties, low-skilled workers are decisive and support a maximum employment protection level together with some unemployment benefit. We now show that equilibria more consistent with empirical evidence emerge in the more realistic framework where politicians are allowed to coalesce into parties. We proceed in two steps. We first show in Proposition 2 that there exists an equilibrium with parties (an EPS as defined in the previous section) where the policy bundle implemented at the equilibrium belongs to the Pareto set of high-ability workers and unemployed. We then present and discuss two assumptions that together guarantee that the only policies proposed in all equilibria with parties belong to the same set (Proposition 3).

Proposition 2 makes use of the following condition: ${ }^{21}$

$\mathbf{C 1} \exists(\tau, \mu) \in P_{\left\{e_{H}, u\right\}}: \mathbf{V}(\tau, \mu, \theta)>\mathbf{V}\left(\hat{\tau}\left(e_{L}\right), \hat{\mu}\left(e_{L}\right), \theta\right), \forall \theta \in\left\{e_{H}, u\right\}$.

Condition $\mathrm{C} 1$ states that high-ability workers and unemployed agents can agree on some policy that both strictly prefer to the most-favored policy of the low-ability workers. As we show formally in Appendix 6, this condition is satisfied provided that $x_{H}$ is large enough that high-ability workers have a very low chance of losing their job and so are concerned mainly with the tax. In that case, high-ability indifference

\footnotetext{
${ }^{21}$ For the sake of generality, we state formally conditions $\mathrm{C} 1$ to $\mathrm{C} 3$ in terms of endogenous policy preferences. We show formally in Result 1 in Appendix sufficient conditions on $x_{H}$ and $\pi(1)$ under which they are satisfied.
} 
curves through point $\left(\hat{\tau}\left(e_{L}\right), \hat{\mu}\left(e_{L}\right)\right)$ are close to vertical (see Figure 1) and both types $e_{H}$ and $u$ would benefit from a decrease in tax accompanied with a large decrease in employment protection.

Proposition 2 (i) If $C 1$ holds, then there exists an $\operatorname{EPS}\left(\pi^{*}, \mathbf{p}^{*}\right)$ such that

$$
\pi^{*}=\left\{\left\{e_{H}, u\right\},\left\{e_{L}\right\},\{c\}\right\}, \text { and } \delta\left(\pi^{*}\right) \subset P_{\left\{e_{H}, u\right\}}
$$

(ii) If $C 1$ does not hold, then $\left(\hat{\tau}\left(e_{L}\right), \hat{\mu}\left(e_{L}\right)\right)$ is the unique policy outcome in all EPSs; that is: in every $\operatorname{EPS}(\pi, \mathbf{p}), \delta(\pi)=\left\{\left(\hat{\tau}\left(e_{L}\right), \hat{\mu}\left(e_{L}\right)\right)\right\}$.

Proposition 2 states that, if $\mathrm{C} 1$ holds, then there exists an EPS where high-ability workers and unemployed coalesce in a party and compete in elections with the lowability workers and capitalists running separately. The party formed by types $e_{H}$ and $u$ wins the election by proposing a policy with some positive tax $\tau^{*}$ and employment protection level $\mu^{*}$ that they both prefer to the most-preferred policy of low-ability workers. Assumption $\mathrm{C} 1$ is crucial since it guarantees the existence of such a policy. Moreover, if $\mathrm{C} 1$ does not hold, then the second part of Proposition 2 shows that the unique policy outcome in all EPS is the most-preferred policy bundle of the low ability workers. The intuitive reason for this result runs as follows. We have assumed that low ability workers form a majority if they join forces with either the high-ability workers or the unemployed. To break the power of the type $e_{L}$, it is then necessary that there exist some policies attainable by a coalition of types $e_{H}$ and $u$ (i.e., in their Pareto set) that they jointly prefer to the most-preferred policy of type $e_{L}$. If this condition does not hold, then type $e_{L}$ can always "divide and rule" by attracting either type $e_{H}$ or type $u$.

We show in the proof of Proposition 2 that, if $\mathrm{C} 1$ holds, then $\left(\tau^{*}, \mu^{*}\right)$ is preferred by a majority of voters to both $\left(\hat{\tau}\left(e_{L}\right), \hat{\mu}\left(e_{L}\right)\right)$ and $(\hat{\tau}(c), \hat{\mu}(c))$ and constitutes an equilibrium of the partition. In other words, the most-preferred policy bundle of types $e_{L}$ is no longer a Condorcet winner when parties are allowed to form and C1 holds, since a majority of voters prefer some policies in the Pareto set of the party made of types $e_{H}$ and $u$.

To prove that this political state is indeed an EPS when $\mathrm{C} 1$ holds, we have to show that no candidate has an incentive to split the party he belongs to, or to join another party or candidate. Types $e_{H}$ and $u$ have no incentive to disband their party, since Proposition 1 has shown that this would result in the most-preferred policy of type $e_{L}$. They also have no incentive to form a larger party (with either type $e_{L}$ or $c$ ), since such a party cannot bring them both a better policy, while they would have to share the spoils of office among a larger number of members. Finally, we show that types $e_{L}$ and $c$ have no incentive to form a party together because 
such a party would have no chance of winning the election. Observe that this last statement holds even in the case where $e_{L}$ and $c$ together represent a majority of the electorate. The reason is that, for any policy $x$ in the Pareto set of $e_{L}$ and $c$, there always exists a policy $y$ in the Pareto set of $e_{H}$ and $u$ that is preferred to $x$ by either $e_{L}$ or $c$ (in addition to $e_{H}$ and $u$ ). Policy $y$ then beats $x$ with a majority constituted of three out of the four types of voters.

In order to prove that the only policies that are proposed in all EPS belong to the Pareto set of the coalition made of high-ability workers together with unemployed agents, we need to impose two further conditions:

C2 $\mathbf{V}\left(\hat{\tau}\left(e_{L}\right), \hat{\mu}\left(e_{L}\right), u\right)>\max _{(\tau, \mu) \in P_{\left\{e_{H}, c\right\}}} \mathbf{V}(\tau, \mu, u)$.

C3 $\forall \tau>\hat{\tau}\left(e_{H}\right), \mathbf{V}\left(\hat{\tau}\left(e_{H}\right), \hat{\mu}\left(e_{H}\right), e_{L}\right)>\mathbf{V}\left(\tau, 0, e_{L}\right)$.

Condition $\mathrm{C} 2$ states that unemployed agents prefer the most-favored policy of low-ability workers to any policy in the Pareto set of the coalition of capitalists and high-quality workers. As for the previous condition, $\mathrm{C} 2$ is satisfied if $x_{H}$ is large enough, so that high-ability workers favor a very low value of the tax (see Result 1 in Appendix 6 for a formal statement and its proof). In that case, all policies in the Pareto set of the coalition made of high-ability workers and capitalists exhibit low values of the tax rates, which are very detrimental to unemployed workers.

Condition C3 states that low-ability workers prefer the most-favored policy of high-ability workers to any policy with no employment protection. This will be the case if, for instance, $\pi(1)$ is close to one, since in that case the most-preferred policy of low-ability and high-ability workers do not differ much from each other (see Result 1 in Appendix 6).

To summarize conditions $\mathrm{C} 1$ and $\mathrm{C} 2$ hold if $x_{H}$ is large enough, while C3 holds if $\pi(1)$ is large enough. Observe that the latter condition is rather innocuous, as we are at liberty to construct the set of admissible policies as we wish. Also, some extremeleft European politicians such as Olivier Besancenot in France clearly advocate such policies, where firing workers would be made illegal except in very extreme circumstances. As for the first condition, it has large empirical support (see Saint-Paul, 2007, Table 5, for the US and for France, for instance).

Given the innocuity or large empirical support for assumptions C1 to C3, we concentrate on the case where they all hold and we obtain: ${ }^{22}$

Proposition 3 If C1-C3 hold then, in every EPS $\left(\pi^{*}, \mathbf{p}^{*}\right),\left(\tau^{*}, \mu^{*}\right) \in \delta\left(\pi^{*}\right)$ implies that:

\footnotetext{
${ }^{22}$ We show in Appendix 7 that other EPS may exist if either $\mathrm{C} 2$ or $\mathrm{C} 3$ is not satified, while $\mathrm{C} 1$ holds.
} 
(i) $\left(\tau^{*}, \mu^{*}\right) \in P_{\left\{e_{H}, u\right\}}$, and

(ii) $\mathbf{V}\left(\tau^{*}, \mu^{*}, \theta\right) \geq \mathbf{V}\left(\hat{\tau}\left(e_{L}\right), \hat{\mu}\left(e_{L}\right), \theta\right), \forall \theta \in\left\{e_{H}, u\right\}$.

We already know from Proposition 2 that, if $\mathrm{C} 1$ holds, there exists at least one EPS where the equilibrium policy belongs to the Pareto set of types $e_{H}$ and $u$. The role played by $\mathrm{C} 3$ in the proof of Proposition 3 is easy to ascertain: it prevents the formation of a coalition made of unemployed individuals and of capitalists, since any such coalition, by proposing no employment protection, would induce the formation of a coalition of (low- and high-ability) workers which would win the elections by proposing the most-preferred policy of the high-ability workers.

The role played by $\mathrm{C} 2$ is more subtle, since this condition, which seems on the face of it to favor the low-ability workers, ends up being detrimental to them. Under C2, low-ability workers are powerful enough to obtain their most-preferred policy when running against both an unemployed candidate and a coalition made of high-ability workers and capitalists. As a consequence, there is no EPS with a partition from which low-ability workers can induce (by splitting a party) this specific partition. At the same type, this partition is not part of an EPS, since the three other types of agents have an incentive to form a party together in order to implement a policy that is in the Pareto set of the unemployed together with the high-ability workers. In other words, C2 makes low-ability workers powerful enough to resist a party made of high-ability and capitalists, but not powerful enough to fend off a grand party made of all other types.

Finally, observe that part (ii) of Proposition 3 puts lower- and upper-bounds on the values of $\tau$ and of $\mu$ that emerge at equilibrium. These bounds are determined by the $e_{H^{-}}$and $u$-politicians' utility levels at the low-ability workers' ideal policy. This policy plays the role of an "outside option" in the platform choice of parties involving those politicians, since they can threaten to break up any party they belong to and induce party structures in which the low-ability workers' ideal policy emerges as the political outcome.

\section{Discussion and Conclusion}

In this paper, we develop a theoretical model consistent with the empirical observation of a negative correlation between EPL and UB across countries. The crucial ingredient in our model is that politicians are allowed to coalesce and form political parties. They then propose policy bundles composed of an UB and EPL and compete in a winner-takes-all election. The importance of party formation can be seen by comparing Propositions 1 and 3. Proposition 1 shows that, when candidates are not allowed to form parties and are restricted to choosing between running on their 
own or not running at all, the unique equilibrium is the most-preferred policy bundle of low-ability workers -i.e., large EPL together with some UB. Proposition 3 shows that, under certain assumptions, this policy bundle is not an equilibrium anymore when candidates are allowed to form parties. In that case the "decisive" party is the one made of high-ability workers together with unemployed. The set of policies proposed at equilibrium by this party exhibits a negative relationship between UB and EPL. We contend that the conditions which guarantee that only equilibria of that type can emerge are either innocuous (the maximum allowable probability that a current worker's job is protected from the firm's firing attempts is large enough) or empirically relevant (high skilled workers have a low probability that the firm would try to fire them).

The rationale we provide for the empirically observed negative relationship between UB and EPL differs from the one provided by Boeri et al. (2011). In their model, low-ability workers are decisive in both the choice of UB and EPL. The negative correlation between UB and EPL is due to their substitutability for the decisive group. Although this substitutability also holds in our model, it is not the main driving force being our results. Coalitional considerations are at the core of our argument, and the negative relationship is driven by the fact that the decisive coalition is made of high-ability workers and unemployed, whose contract curve has precisely this feature.

The fact that the decisive coalition is made of unemployed and of high-ability workers may be surprising on two accounts: first, this coalition is made not only of insiders (who represent a majority of the electorate), but rather of both insiders and outsiders. Second, the insiders who team up with the unemployed are the high ability workers, rather than the low ability workers. This second result is all the more interesting (and surprising) that our model is biased in favor of low-ability workers: we assume that they represent the largest group, and that they constitute a majority when they join forces with either high-ability workers or unemployed (and even may be with capitalists - we make no assumption on the size of this coalition). Our results illustrate that size is not all that matters when political parties are allowed to form.

Although this paper constitutes, to the best of our knowledge, the first attempt to study endogenous parties in the context of labor market policies, we observe that other theoretical papers have come up with majorities made of the same two types of agents. Cahuc and Postel-Vinay (2002) look at who may be in favor of introducing a positive EPL together with short term, flexible work contracts, and obtain that "any worker whose job is not directly threatened by such a reform will be in favor of it. This includes all the unemployed and all long-term job holders, which clearly make a majority." (p. 85) This majority corresponds to the winning coalition obtained in our paper, once we observe that high-ability workers are those with the smallest probability of getting fired. In another context, Vindigni (2008) obtains 
endogenously the same kind of alliance when studying the political determination of the EPL when workers have a large bargaining weight and the economy starts with a low EPL: a group made of unemployed and large productivity workers is then pitted against a group made of low productivity workers.

An open question is of course whether our result that the decisive coalition is made of unemployed and of high ability (and low firing probability) employed has some empirical support. It is difficult to test this proposition, for various reasons. As we have explained in the introduction, our desire to model endogenous parties comes from the observation that it is very difficult to state at the outset which constituency a party represents (such as left parties representing "labor" and right parties representing "capital"). Our results confirm our reluctance to associate ex ante specific parties with constituencies, given the surprising winning coalition that we obtain. This in turn means that to test the empirical validity of our result requires delving into the specifics of each country. Moreover, the large number of dimensions voters care about (beyond labor market policies) makes it difficult to identify who supports a party because of its labor market policies, as opposed to other policies.

This exercise is of course beyond the scope of this paper, but we observe that political scientist David Rueda provides a narrative of labor market policies in Britain which fits quite well with our model and its results (Rueda, 2006). The two dimensions of labor policies on which he focuses are the EPL and active labor market policies (ALMP), rather than unemployment benefits in our model. He observes that, before 1970, in the UK, the employment risks were low so that the Labour party represented workers (or "labour") as an aggregate. He contends that, with the advent of massive unemployment in the 70ies and 80ies, the Labour party has increasingly represented the insiders, at the expense of the unemployed. Although Rueda does not allow explicitly for a separation between low- and high-ability workers, he explains that unions were extremely powerful within the Labour Party ("through the use of "block voting", unions controlled 80 per cent of the votes in Labour party congresses until 1993" p.391), and that "historically, they had advanced the interests of already skilled workers" (p 392), which fits with our description of high-ability workers. Under Labour governments until 1971, EPL was very high, and ALMP nearly non existent. Rueda then states that "the decline of employment protection in Britain coincided with the emergence of New Labour and a distancing between the party and the unions" (p. 393), with the union block voting reduced first to $70 \%$ and then to $50 \%$ (and a similar drop in the union share of party financing). Rueda then describes how New Labour moved away from EPL and towards (ALMP) policies "aimed at young people, single parents, sick and disabled people and the long-term unemployed" (p 394). This narrative fits our model quite well, with the Labour Party representing both skilled workers and unemployed, its policy platform being determined according to the bargaining weight of the unions (representing the skilled 
workers) within the party, and with a lowering of the influence of unions translating in a policy more closely attuned to the preferences of the unemployed, with lower EPL but larger ALMP. ${ }^{23}$

This narrative stresses the importance of the bargaining power of the different factions inside the Labour party. This resonates very well with our approach, where equilibria do exist (notwithstanding the multidimensionality of the policy space) but are typically multiple : while Proposition 3 restricts the set of equilibrium policies to a subset of the contract curve of high-ability workers and unemployed, it does not pinpoint which equilibrium will emerge. More precisely, we are agnostic as to the relative bargaining weight of the two types who constitute this party. Explaining why certain countries end up at a precise location on this contract curve would require to refine the equilibrium concept and to endogenize bargaining weights. We leave this worthwhile but very complex question to future research.

\section{Appendix 1: The Economic Equilibrium}

In this appendix, we show that there exists a lower bound $\bar{\Delta}$ such that the economic equilibrium has the following properties for all policy vectors $(\tau, \mu) \in P$ whenever $\Delta>\bar{\Delta}$ :

(i) Capitalists's consumption (and therefore payoff) is strictly positive;

(ii) It is always optimal for the firm to induce employed workers to invest in firmspecific human capital.

(i) The following condition must be true for capitalists' consumption to be strictly positive:

$$
\left[y+x \Delta-\bar{w}\left(\mu, \tau \frac{1+\kappa}{1-\ell}\right)\right] \frac{\ell}{\kappa}-\tau>0 .
$$

As $\bar{w}$ is strictly increasing in $\mu$ and $\tau$, the above condition holds for any $(\tau, \mu) \in P$ whenever

$$
\Delta>\Delta^{1} \equiv\left\{\bar{\tau} \kappa-\ell\left[y-\bar{w}\left(1, \bar{\tau} \frac{1+\kappa}{1-\ell}\right)\right]\right\}(\ell x)^{-1}
$$

\footnotetext{
${ }^{23} \mathrm{~A}$ more recent example is the last French presidential election, where candidate Sarkozy and his right wing political party have simultaneously proposed policies catering to the employed (by decreasing income taxes on additional hours worked, for instance) while at the same time favoring the flexicurity model (and especially the decrease in EPL). His political campaign has been characterized by the support of personalities known to represent outsiders, such as Martin Hirsch, the former president of Emmaüs France.
} 
(ii) As the utility of capitalists is strictly increasing in consumption, it is optimal for the firm to induce workers to invest in human capital if and only if

$$
\left[y+x \Delta-\bar{w}\left(\mu, \tau \frac{1+\kappa}{1-\ell}\right)\right] \frac{\ell}{\kappa}-\tau \geq\left(y-\rho \tau \frac{1+\kappa}{1-\ell}\right) \frac{\ell}{\kappa}-\tau
$$

or, equivalently,

$$
\Delta \geq x^{-1}\left[\bar{w}\left(\mu, \tau \frac{1+\kappa}{1-\ell}\right)-\rho \tau \frac{1+\kappa}{1-\ell}\right] .
$$

The above condition holds for any $(\tau, \mu) \in P$ whenever

$$
\Delta \geq \Delta^{2} \equiv \max \left\{x^{-1}\left[\bar{w}\left(1, \tau \frac{1+\kappa}{1-\ell}\right)-\rho \tau \frac{1+\kappa}{1-\ell}\right]: \tau \in[0, \bar{\tau}]\right\}
$$

where $\Delta^{2}$ 's existence is guaranteed by Weierstrass Theorem. Setting $\bar{\Delta} \equiv \max \left\{\Delta^{1}, \Delta^{2}\right\}$, we obtain the result.

\section{Appendix 2: Proof of Lemma 1}

A brief observation of policy preferences reveals that, for every $\tau \in[0, \bar{\tau}], \mathbf{V}(\tau, \mu, \theta)$ is strictly increasing everywhere in $\mu$ if $\theta \in\left\{e_{L}, e_{H}\right\}$, and strictly decreasing everywhere if $\theta \in\{u, c\}$. This directly establishes the second statement in the lemma.

Let us turn to ideal tax rates. By strict concavity of $\mathbf{V}\left(\tau, 1, e_{i}\right)$ in $\tau, \hat{\tau}\left(e_{i}\right)$ is implicitly defined as the unique solution to the following equation (assuming an interior solution): $:^{24}$

$$
\frac{\partial \mathbf{V}\left(\tau, 1, e_{i}\right)}{\partial \tau}=-p\left(1, e_{i}\right) U^{\prime}\left(\rho w_{c}-\tau\right)+\left[1-p\left(1, e_{i}\right)\right] U^{\prime}\left(\tau \frac{\ell+\kappa}{1-\ell}\right) \frac{\ell+\kappa}{1-\ell}=0 .
$$

Using the implicit function theorem together with curvature conditions on $U$, we obtain that $0<\hat{\tau}\left(e_{H}\right)<\hat{\tau}\left(e_{L}\right)$.

As $\rho \geq 1, \ell \in(0,1)$, and $U^{\prime}>0$, we also have

$$
\frac{\partial \mathbf{V}(\tau, 0, u)}{\partial \tau}=p(0, u)\left(\rho \frac{1+\kappa}{1-\ell}-1\right) U^{\prime}\left(\rho \tau \frac{1+\kappa}{1-\ell}-\tau\right)+[1-p(0, u)] \frac{\ell+\kappa}{1-\ell} U^{\prime}\left(\tau \frac{\ell+\kappa}{1-\ell}\right)>0
$$

which implies that $\hat{\tau}(u)=\bar{\tau}$.

Finally, capitalists favor a zero tax. Indeed the average wage $\bar{w}$ is strictly increasing in $\tau$, so that income taxation reduces both their pre- and after-tax incomes.

\footnotetext{
${ }^{24}$ Observe that, since $U^{\prime \prime}<0$ and $\lim _{c \rightarrow 0} U^{\prime}(c)=\infty$, this equation has a (unique) solution which is strictly smaller than $\rho w_{c}$. We then assume that $\bar{\tau}$ is larger than this value for $e_{L}$, so that this FOC holds with equality for both $e_{L}$ and $e_{H}$.
} 


\section{Appendix 3: Proof of Proposition 1}

The proof of Proposition 1 hinges on the following result.

Lemma $2\left(\hat{\tau}\left(e_{L}\right), \hat{\mu}\left(e_{L}\right)\right)$ is a strict Condorcet winner in $\{\hat{\tau}(\theta), \hat{\mu}(\theta)\}_{\theta \in \Theta}$.

Proof: To prove Lemma 2, it suffices to check that the following inequalities hold:

$$
\begin{gathered}
\mathbf{V}\left(\hat{\tau}\left(e_{L}\right), \hat{\mu}\left(e_{L}\right), e_{H}\right)>\mathbf{V}\left(\hat{\tau}(u), \hat{\mu}(u), e_{H}\right), \\
\mathbf{V}\left(\hat{\tau}\left(e_{L}\right), \hat{\mu}\left(e_{L}\right), u\right)>\mathbf{V}\left(\hat{\tau}\left(e_{H}\right), \hat{\mu}\left(e_{H}\right), u\right), \\
\mathbf{V}\left(\hat{\tau}\left(e_{L}\right), \hat{\mu}\left(e_{L}\right), u\right)>\mathbf{V}(\hat{\tau}(c), \hat{\mu}(c), u) .
\end{gathered}
$$

To establish (6), note first that

$$
\begin{aligned}
\mathbf{V}\left(\hat{\tau}\left(e_{L}\right), \hat{\mu}\left(e_{L}\right), e_{H}\right)-\mathbf{V}\left(\hat{\tau}(u), \hat{\mu}(u), e_{H}\right) & =\left[\mathbf{V}\left(\hat{\tau}\left(e_{L}\right), 1, e_{H}\right)-\mathbf{V}\left(\hat{\tau}(u), 1, e_{H}\right)\right] \\
& +\left[\mathbf{V}\left(\hat{\tau}(u), 1, e_{H}\right)-\mathbf{V}\left(\hat{\tau}(u), 0, e_{H}\right)\right] .
\end{aligned}
$$

As $\mathbf{V}\left(\tau, \mu, e_{H}\right)$ is strictly increasing in $\mu$, the second bracketed term on the righthand side of the above equality is positive. By the strict concavity of $\mathbf{V}\left(\cdot, 1, e_{H}\right)$, $\mathbf{V}\left(\cdot, 1, e_{H}\right)$ is single-peaked with its peak at $\hat{\tau}\left(e_{H}\right)<\hat{\tau}\left(e_{L}\right)<\hat{\tau}(u)$. This shows that the first bracketed term is also positive, thus proving that the $e_{H}$-politician strictly prefers $\left(\hat{\tau}\left(e_{L}\right), \hat{\mu}\left(e_{L}\right)\right)$ to $(\hat{\tau}(u), \hat{\mu}(u))$.

Inequality (7) results from the facts that $\hat{\mu}\left(e_{L}\right)=\hat{\mu}\left(e_{H}\right), \hat{\tau}\left(e_{L}\right)>\hat{\tau}\left(e_{H}\right)$ (Lemma 1) and that $\mathbf{V}(\tau, \mu, u)$ is strictly increasing in $\tau$ for any value of $\mu$.

Finally, inequality (8) follows from the observation that $U^{\prime}>0$ and that

$\mathbf{V}\left(\hat{\tau}\left(e_{L}\right), \hat{\mu}\left(e_{L}\right), u\right)=p(1, u) U\left(\hat{\tau}\left(e_{L}\right)\left(\rho \frac{1+\kappa}{1-\ell}-1\right)\right)+[1-p(1, u)] U\left(\hat{\tau}\left(e_{L}\right) \frac{\ell+\kappa}{1-\ell}\right)$

where the arguments in both utility functions $U$ are positive, while

$$
\mathbf{V}(\hat{\tau}(c), \hat{\mu}(c), u)=U(0) \text {. }
$$

This ends the proof of Lemma 2.

Proof of Proposition 1:

- One-candidate equilibria

An immediate consequence of Lemma 2 is that there is a unique one-candidate $\pi^{0}$-equilibrium, in which the $e_{L}$-politician runs alone and implements her ideal policy. 


\section{- Two-candidate equilibria}

By assumption, parties who are indifferent between running and not running choose not to run. As a consequence, a situation in which a candidate loses with a probability of one cannot be an equilibrium. Combined with Lemma 2, this observation implies that there is no two-candidate $\pi^{0}$-equilibrium in which the $e_{L^{-}}$ politician runs.

The $e_{H^{-}}$and $c$-politicians running against each other cannot be an equilibrium, since $\ell>(1+\kappa) / 2$ and an argument similar to the one made in the proof of inequality (6) in Lemma 1 establishes that voters of type $e_{L}$ strictly prefer $\left(\hat{\tau}\left(e_{H}\right), \hat{\mu}\left(e_{H}\right)\right)$ to $(\hat{\tau}(c), \hat{\mu}(c))$.

Suppose now that the two running candidates are the $u$ - and $c$-politicians. If the voters of type $e_{L}$ strictly prefer $(\hat{\tau}(u), \hat{\mu}(u))$ to $(\hat{\tau}(c), \hat{\mu}(c))$, then the $u$-politician wins for sure since, by assumption, $1-\lambda \ell>(1+\kappa) / 2$. If they instead (weakly) prefer $(\hat{\tau}(c), \hat{\mu}(c))$ to $(\hat{\tau}(u), \hat{\mu}(u))$, then the $e_{H}$-politician has a profitable deviation. Indeed, the latter could run and get the votes of voters of type $e_{L}$ who strictly prefer $\left(\hat{\tau}\left(e_{H}\right), \hat{\mu}\left(e_{H}\right)\right)$ to $(\hat{\tau}(c), \hat{\mu}(c))$ and therefore to $(\hat{\tau}(u), \hat{\mu}(u))$. This would thus enable her to implement her ideal policy with a probability of 1 .

Finally, the $e_{H^{-}}$and $u$-politicians running against each other cannot be a $\pi_{0^{-}}$ equilibrium either. To see this, note first that a tie between these two candidates requires that voters of type $e_{L}$ to be indifferent between $(\hat{\tau}(u), \hat{\mu}(u))$ and $\left(\hat{\tau}\left(e_{H}\right), \hat{\mu}\left(e_{H}\right)\right)$. If type- $c$ voters prefer $(\hat{\tau}(u), \hat{\mu}(u))$ to $\left(\hat{\tau}\left(e_{H}\right), \hat{\mu}\left(e_{H}\right)\right)$, then the $e_{L}$-politician has a profitable deviation. She can indeed enter the electoral competition and implement her ideal policy since $(1-\lambda) \ell>\lambda \ell=\kappa+1-\ell$. If type- $c$ voters are indifferent between $(\hat{\tau}(u), \hat{\mu}(u))$ and $\left(\hat{\tau}\left(e_{H}\right), \hat{\mu}\left(e_{H}\right)\right)$, then the $e_{L}$-politician enters and wins since $(1-\lambda) \ell>1-\ell+\frac{\kappa}{2}=\lambda \ell+\frac{\kappa}{2}$. If type- $c$ voters strictly prefer $\left(\hat{\tau}\left(e_{H}\right), \hat{\mu}\left(e_{H}\right)\right)$ to $(\hat{\tau}(u), \hat{\mu}(u))$, then the $e_{L}$-politician can also profitably enter since, in that case, $(1-\lambda) \ell>1-\ell=\kappa+\lambda \ell$ (Assumption 1(a)).

\section{- Three-candidate equilibria}

From our assumptions on the distribution of types, three-candidate elections in which the $e_{L}$-politician runs cannot be equilibrium situations (at least one running candidate would loose for sure).

Consider now the case where the $e_{H^{-}}, u$, and $c$-politicians run against each other. It must be the case that the three politicians tie for winning. But then the $e_{L}$-politician should enter the contest and win for sure since the low-ability employed outnumber all the other types of voters.

- Four-candidate equilibria

There cannot be a four-candidate equilibrium, for some candidates would loose for sure in such an equilibrium (Assumption 1(a)). 


\section{Appendix 4: Proof of Proposition 2}

Hereafter, we use the following notation:

$$
\begin{array}{rll}
\pi^{1} \equiv\left\{\left\{e_{H}, e_{L}\right\},\{u\},\{c\}\right\} & , & \pi^{2} \equiv\left\{\left\{e_{H}\right\},\left\{e_{L}, u\right\},\{c\}\right\} \\
\pi^{3} \equiv\left\{\left\{e_{H}\right\},\left\{e_{L}, c\right\},\{u\}\right\} & , & \pi^{4} \equiv\left\{\left\{e_{H}, u\right\},\left\{e_{L}\right\},\{c\}\right\} \\
\pi^{5} \equiv\left\{\left\{e_{H}, c\right\},\left\{e_{L}\right\},\{u\}\right\} & , & \pi^{6} \equiv\left\{\left\{e_{H}\right\},\left\{e_{L}\right\},\{u, c\}\right\} \\
\pi^{7} \equiv\left\{\left\{e_{H}, e_{L}\right\},\{u, c\}\right\} & , & \pi^{8} \equiv\left\{\left\{e_{H}, c\right\},\left\{e_{L}, u\right\}\right\} \\
\pi^{9} \equiv\left\{\left\{e_{H}, u\right\},\left\{e_{L}, c\right\}\right\} & , & \pi^{10} \equiv\left\{\left\{e_{H}, e_{L}, u\right\},\{c\}\right\} \\
\pi^{11} \equiv\left\{\left\{e_{H}, e_{L}, c\right\},\{u\}\right\} & , & \pi^{12} \equiv\left\{\left\{e_{H}, u, c\right\},\left\{e_{L}\right\}\right\} \\
\pi^{13} \equiv\left\{\left\{e_{H}\right\},\left\{e_{L}, u, c\right\}\right\} & , & \pi^{14} \equiv\left\{\left\{e_{H}, e_{L}, u, c\right\}\right\}
\end{array}
$$

The following two lemmas are used in the proofs of both Proposition 2 and Proposition 3:

Lemma 3 Suppose C1 holds. Then the following statements are true:

(i) $P_{\left\{e_{H}, u\right\}} \supseteq \delta\left(\pi^{4}\right) \neq \emptyset$.

(ii) For any $j \in\{4,12\},(\tau, \mu) \in \delta\left(\pi^{j}\right)$ only if

$$
\mathbf{V}(\tau, \mu, \theta) \geq \mathbf{V}\left(\hat{\tau}\left(e_{L}\right), \hat{\mu}\left(e_{L}\right), \theta\right), \forall \theta \in\left\{e_{H}, u\right\}
$$

(iii) If (9) holds with a strict inequality, then $(\tau, \mu) \in \delta\left(\pi^{4}\right) \cap \delta\left(\pi^{12}\right)$.

(iv) There is no EPS involving $\pi^{12}$.

Proof: Note first that, since $(1-\lambda) \ell>\kappa$, there cannot be three-candidate $\pi^{4}$-equilibria. To prove the first part of the lemma, therefore, it suffices to show that there exists $\left(\tau_{1}, \mu_{1}\right) \in P_{\left\{e_{H}, u\right\}}$ that is a strict Condorcet winner in $\left\{\left(\tau_{1}, \mu_{1}\right)\right.$, $\left.\left(\hat{\tau}\left(e_{L}\right), \hat{\mu}\left(e_{L}\right)\right),(\hat{\tau}(c), \hat{\mu}(c))\right\}$.

From C1, there exists $\left(\tau_{1}, \mu_{1}\right) \in P_{\left\{e_{H}, u\right\}}$, which is preferred to $\left(\hat{\tau}\left(e_{L}\right), \hat{\mu}\left(e_{L}\right)\right)$ by voters of type $e_{H}$ and $u$. As a consequence, $\left(\tau_{1}, \mu_{1}\right)$ must satisfy

$$
0<\tau_{1}<\hat{\tau}\left(e_{L}\right) \text { and } 0 \leq \mu_{1}<\hat{\mu}\left(e_{L}\right) .
$$

This implies that voters of type $c$ also strictly prefer $\left(\tau_{1}, \mu_{1}\right)$ to $\left(\hat{\tau}\left(e_{L}\right), \hat{\mu}\left(e_{L}\right)\right)$, thus proving that the former is majority-preferred to the latter. Furthermore, the inequalities in (10) also guarantee that voters of type $e_{L}$ strictly prefer $\left(\tau_{1}, \mu_{1}\right)$ to $(\hat{\tau}(c), \hat{\mu}(c))$. Inequality (8) shows that type $u$ prefers $\left(\hat{\tau}\left(e_{L}\right), \hat{\mu}\left(e_{L}\right)\right)$ to $(\hat{\tau}(c), \hat{\mu}(c))$, and since they also prefer $\left(\tau_{1}, \mu_{1}\right)$ to $\left(\hat{\tau}\left(e_{L}\right), \hat{\mu}\left(e_{L}\right)\right)$, we obtain that a majority formed of types $e_{L}$ and $u$ prefer $\left(\tau_{1}, \mu_{1}\right)$ to $(\hat{\tau}(c), \hat{\mu}(c))$. This establishes part (i). 
Part (ii) follows directly from part (i) and from the fact that $\left\{e_{H}, e_{L}\right\}$ and $\left\{u, e_{L}\right\}$ are majority coalitions.

If (9) holds with a strict inequality, then we can apply to $(\tau, \mu)$ the same argument as in the proof of part (i) to show that $(\tau, \mu)$ is both a $\pi^{4}$ - and a $\pi^{12}$-equilibrium policy, proving part (iii).

Finally, consider party structure $\pi^{12}$ and a political state in which party $\left\{e_{H}, u, c\right\}$ offers a policy $(\tau, \mu)$. From part (ii), this implies that $(\tau, \mu)$ must satisfy $(9)$. From part (iii) and (C1), this in turn implies that, by definition of $P_{\left\{e_{H}, u\right\}}$, there exists $\left(\tau^{\prime}, \mu^{\prime}\right) \in \delta\left(\pi^{4}\right)$ and a sufficiently small $\varepsilon \in(0, b / 6)$ such that:

$$
\mathbf{V}\left(\tau^{\prime}, \mu^{\prime}, \theta\right)>\mathbf{V}(\tau, \mu, \theta)-\varepsilon
$$

for each $\theta \in\left\{e_{H}, u\right\}$. As a consequence, coalition $\left\{e_{H}, u\right\}$ can profitably deviate by inducing $\pi^{4}$ and then $\left(\tau^{\prime}, \mu^{\prime}\right)$. This indeed makes all its members strictly better-off as they thereby increase their non-policy benefit by $(b / 2)-(b / 3)=b / 6>\varepsilon$.

Lemma $4 \delta\left(\pi^{9}\right)=\emptyset$.

Proof: We first establish that if $(\tau, \mu) \in \delta\left(\pi^{9}\right)$, then $(\tau, \mu) \in P_{\left\{e_{H}, u\right\}}$. Suppose that party $\left\{e_{L}, c\right\}$ offers a policy $(\tau, \mu)$ in $P_{\left\{e_{L}, c\right\}} \backslash P_{\left\{e_{H}, u\right\}}$. Hence, either $(\tau, \mu) \in$ $P_{1} \equiv P_{\left\{e_{L}, c\right\}} \backslash P_{\left\{e_{H}, e_{L}, u\right\}}$ or $(\tau, \mu) \in P_{2} \equiv P_{\left\{e_{L}, c\right\}} \backslash P_{\left\{e_{H}, c, u\right\}}$. In both cases, there is consequently a policy $\left(\tau^{\prime}, \mu^{\prime}\right)$ that makes a majority better-off than under $(\tau, \mu)$. It is easy to check that there is always such a policy in $P_{\left\{e_{H}, u\right\}}$. This implies that party $\left\{e_{H}, u\right\}$ has a profitable deviation whenever party $\left\{e_{L}, c\right\}$ runs alone and offers a policy that does not belong to $P_{\left\{e_{H}, u\right\}}$.

A tie between the two parties in $\pi^{9}$ is impossible when party $\left\{e_{L}, c\right\}$ offers a policy $(\tau, \mu)$ in $P_{\left\{e_{L}, c\right\}} \backslash P_{\left\{e_{H}, u\right\}}$. From our assumptions on the distribution of types, a tie would indeed imply that each politician (and then each type of voter) strictly prefers her party's platform to the rival's platform. Let $\left(\tau_{1}, \mu_{1}\right)$ and $\left(\tau_{2}, \mu_{2}\right)$ be parties $\left\{e_{H}, u\right\}$ ' and $\left\{e_{L}, c\right\}$ 's platforms, respectively. If $\left(\tau_{2}, \mu_{2}\right) \in P_{2}$, this implies that

$$
\tau_{1}<\tau_{2} \text {, and } \mu_{1}<\mu_{2}
$$

which in turn implies that type- $c$ voters strictly prefer $\left(\tau_{1}, \mu_{1}\right)$ to $\left(\tau_{2}, \mu_{2}\right)$; a contradiction. Instead, if $\left(\tau_{2}, \mu_{2}\right) \in P_{1}$, then $\tau_{2}<\tau_{1}$, and $\mu_{1}>\mu_{2}$. As the marginal benefits of $\tau$ and $\mu$ are lower for $e_{H}$ than for $e_{L}, \mathbf{V}\left(\tau_{1}, \mu_{1}, e_{H}\right)>\mathbf{V}\left(\tau_{2}, \mu_{2}, e_{H}\right)$ implies $\mathbf{V}\left(\tau_{1}, \mu_{1}, e_{L}\right)>\mathbf{V}\left(\tau_{2}, \mu_{2}, e_{L}\right)$; a contradiction. As a consequence, a tie must involve the two parties offering $\{(\breve{\tau}, \breve{\mu})\} \equiv P_{\left\{e_{H}, u\right\}} \cap P_{\left\{e_{L}, c\right\}}$ and is therefore inconsistent with the partisan-equilibrium restriction. 
Finally, if party $\left\{e_{H}, u\right\}$ runs alone and offers a policy $(\tau, \mu) \neq(\breve{\tau}, \breve{\mu})$, then party $\left\{e_{L}, c\right\}$ can defeat it by offering $(\breve{\tau}, \breve{\mu})$. If $\left\{e_{H}, u\right\}$ runs alone and offers $(\breve{\tau}, \breve{\mu})$, then $\left\{e_{L}, c\right\}$ can again profitably deviate by offering $(\breve{\tau}, \breve{\mu})$. This does not change the electoral outcome but raises its members' non-policy benefit by $b / 4$.

Proof of Proposition 2: (i) Note first that by condition C1 and Lemma 3 (iii) there exists a $\pi^{4}$-equilibrium in which the $e_{H^{-}}$and $u$-politicians are strictly betteroff than under $\left(\hat{\tau}\left(e_{L}\right), \hat{\mu}\left(e_{L}\right)\right)$. This implies that none of them has an incentive to induce $\pi^{0}$. Further, since the policy they implement in the $\pi^{4}$-equilibrium must belong to their Pareto set, they cannot profitably induce a party structure in which they would have coalesced with other politicians. This would indeed make at least one of them as well- or worse-off and would also reduce their non-policy benefits.

What remains to be proved, therefore, is that $\left\{e_{L}, c\right\}$ cannot profitably induce $\pi^{9}$. This is a direct consequence of Lemma 4 .

(ii) If condition $\mathrm{C} 1$ does not hold, then the following is true for all $(\tau, \mu) \in P_{\left\{e_{H}, u\right\}}$ :

$$
\mathbf{V}\left(\hat{\tau}\left(e_{L}\right), \hat{\mu}\left(e_{L}\right), \theta\right) \geq \mathbf{V}(\tau, \mu, \theta) \text { for some } \theta \in\left\{e_{H}, u\right\} .
$$

As $\left(\hat{\tau}\left(e_{L}\right), \hat{\mu}\left(e_{L}\right)\right) \notin P_{\left\{e_{H}, u\right\}}$, this implies that, for all $(\tau, \mu) \in P_{\left\{e_{H}, u\right\}}$, at least one member of $\left\{e_{H}, u\right\}$ strictly prefers $\left(\hat{\tau}\left(e_{L}\right), \hat{\mu}\left(e_{L}\right)\right)$ to $(\tau, \mu)$. To see this, suppose by contradiction, that there exists $(\tau, \mu) \in P_{\left\{e_{H}, u\right\}}$ such that both members of $\left\{e_{H}, u\right\}$ are indifferent between $\left(\hat{\tau}\left(e_{L}\right), \hat{\mu}\left(e_{L}\right)\right)$ and $(\tau, \mu)$. Our curvature conditions on payoff functions then imply that $\left(\alpha \hat{\tau}\left(e_{L}\right)+(1-\alpha) \tau, \alpha \hat{\mu}\left(e_{L}\right)+(1-\alpha) \mu\right)$, $\alpha \in(0,1)$, is strictly preferred to $\left(\hat{\tau}\left(e_{L}\right), \hat{\mu}\left(e_{L}\right)\right)$ by both $e_{H}$ and $u$; a contradiction with $(\tau, \mu) \in P_{\left\{e_{H}, u\right\}}$. Thus, when C1 does not hold, $\left(\hat{\tau}\left(e_{L}\right), \hat{\mu}\left(e_{L}\right)\right)$ is a Condorcet winner in $P_{\left\{e_{H}, u\right\}} \cup\left\{\left(\hat{\tau}\left(e_{L}\right), \hat{\mu}\left(e_{L}\right)\right)\right\}$ (recall that $\left\{e_{H}, e_{L}\right\}$ and $\left\{e_{L}, u\right\}$ are both majority coalitions). We now use this result to prove the following

Claim 1: If C1 does not hold, then $\delta\left(\pi^{j}\right)=\left\{\left(\hat{\tau}\left(e_{L}\right), \hat{\mu}\left(e_{L}\right)\right)\right\}$ for any $j \in$ $\{4,5,6,12\}$.

We start with party structure $\pi^{4}$. By the same logic as in the proof of Lemma 3 (i), there cannot be a $\pi^{4}$-equilibrium in which the three parties run. As $\left(\hat{\tau}\left(e_{L}\right), \hat{\mu}\left(e_{L}\right)\right)$ is majority preferred to $(\hat{\tau}(c), \hat{\mu}(c))$ (Lemma 2) and to all elements of $P_{\left\{e_{H}, u\right\}}$, this implies that $\delta\left(\pi^{4}\right)=\left\{\left(\hat{\tau}\left(e_{L}\right), \hat{\mu}\left(e_{L}\right)\right)\right\}$.

Consider now party structure $\pi^{5}$. By the same logic as in the proof of Lemma 5 , only two parties may run in a $\pi^{5}$-equilibrium: $\left\{e_{H}, c\right\}$ and $\left\{e_{L}\right\}$ (Note that this does not depend on whether $\mathrm{C} 2$ holds or not). Suppose that, contrary to the statement of the Claim, party $\left\{e_{H}, c\right\}$ offers a policy $(\tau, \mu)$ in a $\pi^{5}$-equilibrium. This implies that both the $e_{H^{-}}$and the $u$-politicians (weakly) prefer $(\tau, \mu)$ to $\left(\hat{\tau}\left(e_{L}\right), \hat{\mu}\left(e_{L}\right)\right)$ (otherwise, $\left\{e_{L}\right\}$ could win for sure). By definition of a Pareto set, there must be 
an alternative $\left(\tau^{\prime}, \mu^{\prime}\right) \in P_{\left\{e_{H}, u\right\}}$ (which may coincide with $(\tau, \mu)$ ) such that both type- $e_{H}$ and type- $u$ voters (weakly) prefer $\left(\tau^{\prime}, \mu^{\prime}\right)$ to $\left(\hat{\tau}\left(e_{L}\right), \hat{\mu}\left(e_{L}\right)\right)$; a contradiction with the assumption that $\mathrm{C} 1$ does not hold.

By the same reasoning as in the proof of Proposition 3, at most two parties can run in a $\pi^{6}$-equilibrium. We first prove that $\left\{\varnothing,\left(\hat{\tau}\left(e_{L}\right), \hat{\mu}\left(e_{L}\right)\right), \varnothing\right\}$ is a $\pi^{6}$ equilibrium. If a party $S \neq\left\{e_{L}\right\}$ had a profitable deviation, this would mean that there is a policy in its Pareto set that can get the support both $e_{H^{-}}$and $u$-voters against $\left(\hat{\tau}\left(e_{L}\right), \hat{\mu}\left(e_{L}\right)\right)$. But this would in turn imply that there also exists a policy in $P_{\left\{e_{H}, u\right\}}$ which is weakly preferred to $\left(\hat{\tau}\left(e_{L}\right), \hat{\mu}\left(e_{L}\right)\right)$ by all members of $\left\{e_{H}, u\right\}$; a contradiction with the assumption that $\mathrm{C} 1$ does not hold. By the same logic, we can rule out $\pi^{6}$-equilibria in which a party $S \neq\left\{e_{L}\right\}$ runs alone or against $\left\{e_{L}\right\}$. The only remaining case is of the form $\left\{\left(\hat{\tau}\left(e_{H}\right), \hat{\mu}\left(e_{H}\right)\right), \varnothing,(\tau, \mu)\right\}$. This would require voters of type $e_{L}$ to be indifferent between $\left(\hat{\tau}\left(e_{H}\right), \hat{\mu}\left(e_{H}\right)\right)$ and $(\tau, \mu)$, and therefore that $\lambda \ell=1-\ell+\kappa$. As $\lambda<1 / 2$, we therefore have $(1-\lambda) \ell>\lambda \ell=1-\ell+\kappa$. The $e_{L}$ could therefore profitably deviate by offering $e_{L}$-voters' ideal policy. This shows that $\left(\hat{\tau}\left(e_{L}\right), \hat{\mu}\left(e_{L}\right)\right)$ is only possible policy outcome in a $\pi^{6}$-equilibrium.

Finally, consider party structure $\pi^{12}$. Suppose that, contrary to the statement of the claim, there is a $\pi^{12}$-equilibrium in which party $\left\{e_{H}, u, c\right\}$ runs and offers a policy $(\tau, \mu) \in P_{\left\{e_{H}, u, c\right\}}$. This implies that voters of types $e_{H}$ and $u$ prefer $(\tau, \mu)$ to $\left(\hat{\tau}\left(e_{L}\right), \hat{\mu}\left(e_{L}\right)\right)$. By definition of $P_{\left\{e_{H}, u\right\}}$, however, this implies that there exists $\left(\tau^{\prime}, \mu^{\prime}\right) \in P_{\left\{e_{H}, u\right\}}$ such voters of types $e_{H}$ and $u$ also (weakly) prefer $\left(\tau^{\prime}, \mu^{\prime}\right)$ to $\left(\hat{\tau}\left(e_{L}\right), \hat{\mu}\left(e_{L}\right)\right)$; a contradiction. Hence, party $\left\{e_{L}\right\}$ running unopposed is the only $\pi^{12}$-equilibrium.

To see that there exists an EPS $(\pi, \mathbf{p})$ in which $\left(\hat{\tau}\left(e_{L}\right), \hat{\mu}\left(e_{L}\right)\right)$ is the unique policy outcome, consider party structure $\pi^{0}$. From Proposition $1, \delta\left(\pi^{0}\right)=\left\{\left(\hat{\tau}\left(e_{L}\right), \hat{\mu}\left(e_{L}\right)\right)\right\}$. In this $\pi^{0}$-equilibrium, the $e_{L}$-politician can implement her ideal policy and obtain the entire benefit $b$. Hence, she will never agree to induce another party structure. The only coalitional deviations from $\pi^{0}$ we need to consider are therefore to $\pi^{4}, \pi^{5}$, $\pi^{6}$, and $\pi^{12}$. But we know from Claim 1 that such deviations would yield the same outcome as in $\pi^{0}$. This proves that $\left(\pi^{0},\left\{\varnothing,\left(\hat{\tau}\left(e_{L}\right), \hat{\mu}\left(e_{L}\right)\right), \varnothing, \varnothing\right\}\right)$ is an EPS.

We now complete the proof of part (ii) of Proposition 2 by showing that there is no EPS involving party structures in $\left\{\pi^{j}: j=1,2,3,7,8,9,10,11,13,14\right\}$. The $e_{L^{-}}$ politician can induce $\pi^{6}$ from $\pi^{7}$ and $\pi^{13}, \pi^{5}$ from $\pi^{8}$ and $\pi^{11}, \pi^{4}$ from $\pi^{10}, \pi^{12}$ from $\pi^{14}$, and $\pi^{0}$ from any structure in $\left\{\pi^{j}: j=1,2,3\right\}$. By Claim 1, such deviations would always be profitable to the $e_{L}$-politician, for they would allow her to enforce her ideal policy without having to share the non-policy benefit $b>0$. Finally, $\delta\left(\pi^{9}\right)=\emptyset($ Lemma 4$)$. 


\section{Appendix 5: Proof of Proposition 3}

We start with the following lemma:

Lemma 5 If C2 holds, then $\delta\left(\pi^{5}\right)=\left\{\left(\hat{\tau}\left(e_{L}\right), \hat{\mu}\left(e_{L}\right)\right)\right\}$.

Proof: First of all, note that there cannot be a three-candidate $\pi^{5}$-equilibrium since $(1-\lambda) \ell>1-\ell$. Neither can there be a $\pi^{5}$-equilibrium of the form $\{(\tau, \mu), \varnothing$, $(\hat{\tau}(u), \hat{\mu}(u))\}$. This would indeed require voters of type $e_{L}$ to be indifferent between the platforms offered by $\left\{e_{H}, c\right\}$ and $\{u\}$, and therefore that $\lambda \ell+\kappa=1-\ell$. As $(1-\lambda) \ell>1-\ell,\left\{e_{L}\right\}$ would consequently have a profitable deviation.

Condition $\mathrm{C} 2$ guarantees that $\left(\hat{\tau}\left(e_{L}\right), \hat{\mu}\left(e_{L}\right)\right)$ is strict a Condorcet winner in $P_{\left\{e_{H}, c\right\}} \cup\left\{\left(\hat{\tau}\left(e_{L}\right), \hat{\mu}\left(e_{L}\right)\right)\right\} \cup\{(\hat{\tau}(u), \hat{\mu}(u))\}$. This implies that $\left\{e_{L}\right\}$ running alone and implementing her ideal policy is the unique $\pi^{5}$-equilibrium, thus completing the proof of the lemma.

Proof of Proposition 3: We proceed by proving that conditions C1-C3 imply that the following statement is true for every $j=0, \ldots, 14$ :

$\left(\mathbf{S}^{j}\right)$ If $\left(\tau^{*}, \mu^{*}\right)$ is a policy that emerges with a positive probability in an EPS $\left(\pi^{j}, \mathbf{p}^{*}\right)$, then $\left(\tau^{*}, \mu^{*}\right) \in P_{\left\{e_{H}, u\right\}}$, and

$$
\mathbf{V}\left(\tau^{*}, \mu^{*}, \theta\right) \geq \mathbf{V}\left(\hat{\tau}\left(e_{L}\right), \hat{\mu}\left(e_{L}\right), \theta\right), \forall \theta \in\left\{e_{H}, u\right\}
$$

$\left(\mathbf{S}^{j}\right)$ is evidently true for $j=1,2,3$ since we know from Proposition 1 that the $e_{L}$-politician can always profitably induce $\pi^{0}$. Let us now study the other party structures.

- $j=0$

By condition $\mathrm{C} 1$ and part (iii) in Lemma 3, coalition $\left\{e_{H}, u\right\}$ can profitably induce $\pi^{4}$. This proves that there is no EPS involving $\pi^{0}$.

- $j=4$

$\left(\mathbf{S}^{4}\right)$ is a direct corollary of part (i) in Lemma 3.

- $j=5$

Suppose $\left(\pi^{5}, \mathbf{p}\right)$ is an EPS. We know from Lemma 5 that this implies that $\mathbf{p}=$ $\left\{\varnothing,\left(\hat{\tau}\left(e_{L}\right), \hat{\mu}\left(e_{L}\right)\right), \varnothing\right\}$. By Lemma 3 (iii) and condition $\mathrm{C} 1$, therefore, $\left\{e_{H}, u, c\right\}$ can profitably induce $\pi^{12}$; a contradiction with $\left(\pi^{5}, \mathbf{p}\right)$ being an EPS.

- $j=6$

A tie between the three parties in $\pi^{6}$ is impossible since the low-ability workers outnumber the high-ability workers. 
Suppose that $\left\{e_{H}\right\}$ and $\left\{e_{L}\right\}$ run against each other. This cannot be an equilibrium situation since voters of type $u$ strictly prefer $\left(\hat{\tau}\left(e_{L}\right), \hat{\mu}\left(e_{L}\right)\right)$ to $\left(\hat{\tau}\left(e_{H}\right), \hat{\mu}\left(e_{H}\right)\right)$ and $(1-\lambda) \ell+1-\ell>(1+\kappa) / 2$. Moreover, this also proves that $\left\{e_{H}\right\}$ running alone cannot be a $\pi^{6}$-equilibrium.

Condition C3 ensures that voters of type $e_{L}$ strictly prefer $\left(\hat{\tau}\left(e_{H}\right), \hat{\mu}\left(e_{H}\right)\right)$ to any policy in $P_{\{u, c\}}$. As a consequence, there cannot be equilibria of the form $\{\varnothing, \varnothing,(\tau, \mu)\}$, or $\left\{\left(\hat{\tau}\left(e_{H}\right), \hat{\mu}\left(e_{H}\right)\right), \varnothing,(\tau, \mu)\right\},(\tau, \mu) \in P_{\{u, c\}}$.

Consider now a political state of the form $\left(\pi^{6}, \mathbf{p}\right)$. An immediate consequence of the previous paragraphs is that either $\mathbf{p}=\left\{\varnothing,\left(\hat{\tau}\left(e_{L}\right), \hat{\mu}\left(e_{L}\right)\right), \varnothing\right\}$ or $\mathbf{p}=$ $\left\{\varnothing,\left(\hat{\tau}\left(e_{L}\right), \hat{\mu}\left(e_{L}\right)\right),(\tau, 0)\right\},(\tau, 0) \in P_{\{u, c\}}$. In the former case, $\left(\pi^{6}, \mathbf{p}\right)$ cannot be an EPS as coalition $\left\{e_{H}, u, c\right\}$ can profitably induce $\pi^{12}$ (Lemma 3 (iii) and condition $\mathrm{C} 1$ ).

In the latter case, voters of type $e_{H}$ must be indifferent between $\left(\hat{\tau}\left(e_{L}\right), \hat{\mu}\left(e_{L}\right)\right)$ and $(\tau, 0)$ (otherwise one of the two candidates would win for sure), and voters of types $u$ and $c$ must strictly prefer $(\tau, 0)$ to $\left(\hat{\tau}\left(e_{L}\right), \hat{\mu}\left(e_{L}\right)\right)$. By continuity, there consequently exists a sufficiently small $\varepsilon>0$ such that

$\mathbf{V}(\tau, \varepsilon, \theta) \approx \mathbf{V}(\tau, 0, \theta)>\frac{1}{2} \mathbf{V}(\tau, 0, \theta)+\frac{1}{2} \mathbf{V}\left(\hat{\tau}\left(e_{L}\right), \hat{\mu}\left(e_{L}\right), \theta\right)>\mathbf{V}\left(\hat{\tau}\left(e_{L}\right), \hat{\mu}\left(e_{L}\right), \theta\right)$

for each $\theta \in\{u, c\}$, and

$$
\mathbf{V}\left(\tau, \varepsilon, e_{H}\right)>\mathbf{V}\left(\tau, 0, e_{H}\right)=\mathbf{V}\left(\hat{\tau}\left(e_{L}\right), \hat{\mu}\left(e_{L}\right), e_{H}\right) .
$$

If $(\tau, \varepsilon) \in P_{\left\{e_{H}, u, c\right\}}$, then $(\tau, \varepsilon) \in \delta\left(\pi^{12}\right)$. Otherwise, by continuity of $\mathbf{V}$ and compactness of $P$, there exists $\left(\tau^{\prime}, \mu^{\prime}\right) \in P_{\left\{e_{H}, u, c\right\}}$ which is weakly preferred to $(\tau, \varepsilon)$ by all members of $\left\{e_{H}, u, c\right\}$ and therefore belongs to $\delta\left(\pi^{12}\right)$.

Coalition $\left\{e_{H}, u, c\right\}$ can thus profitably induce $\pi^{12}$. Indeed, this makes all its members better-off in utility terms and also raises their non-policy benefits (by $b / 3-b / 4$ for the $u$ - and $c$-politicians and by $b / 3$ for the $e_{H}$-politician).

- $j=7$

A $\pi^{7}$-equilibrium must involve $\left\{e_{H}, e_{L}\right\}$ running alone: if $\{u, c\}$ offers a policy $(\tau, 0)$, then $\left\{e_{H}, e_{L}\right\}$ can win for sure by offering $\left(\max \left\{\tau, \hat{\tau}\left(e_{H}\right)\right\}, 1\right)$ if $\tau \leq \hat{\tau}\left(e_{L}\right)$, and $\left(\hat{\tau}\left(e_{L}\right), 1\right)$ otherwise. Hence, $\delta\left(\pi^{7}\right) \subseteq P_{\left\{e_{H}, e_{L}\right\}}$.

Suppose first that party $\left\{e_{H}, e_{L}\right\}$ implements a policy $(\tau, 1)$ with $\tau<\hat{\tau}\left(e_{L}\right)$. Given that $\left(\hat{\tau}\left(e_{L}\right), \hat{\mu}\left(e_{L}\right)\right)$ is the $u$-politician's ideal policy in $P_{\left\{e_{H}, e_{L}\right\}}$, the latter should induce $\pi^{1}$ since a direct consequence of Lemma 2 is that party $\left\{e_{H}, e_{L}\right\}$ running alone and implementing $\left(\hat{\tau}\left(e_{L}\right), \hat{\mu}\left(e_{L}\right)\right)$ is a $\pi^{1}$-equilibrium.

Furthermore, there exists by continuity a sufficiently small $\epsilon>0$ such that $\left(\hat{\tau}\left(e_{L}\right)-\epsilon, \hat{\mu}\left(e_{L}\right)\right) \in P_{\left\{e_{H}, e_{L}\right\}}$ also defeats $u$ ' and $c$ 's ideal policies in a pairwise vote. This implies that $\left(\hat{\tau}\left(e_{L}\right)-\epsilon, \hat{\mu}\left(e_{L}\right)\right) \in \delta\left(\pi^{1}\right)$. Suppose now that $\left\{e_{H}, e_{L}\right\}$ implements $\left(\hat{\tau}\left(e_{L}\right), \hat{\mu}\left(e_{L}\right)\right)$ in a $\pi^{7}$-equilibrium. The $c$-politician can profitably induce $\pi^{1}$, for she strictly prefers $\left(\hat{\tau}\left(e_{L}\right)-\epsilon, \hat{\mu}\left(e_{L}\right)\right)$ to $\left(\hat{\tau}\left(e_{L}\right), \hat{\mu}\left(e_{L}\right)\right)$. 
- $j=8$

From Lemma 5, there cannot be an EPS involving $\pi^{8}$ since the $e_{L}$-politician is always better-off inducing $\pi^{5}$.

- $j=9$

$\left(\mathbf{S}^{9}\right)$ is a trivial consequence of Lemma 4.

- $j=10$

In a $\pi^{10}$-equilibrium, $\left\{e_{H}, e_{L}, u\right\}$ must win for sure. For $\left(\pi^{10},((\tau, \mu), \varnothing)\right)$ to be an EPS, however, the following must hold:

$$
\mathbf{V}\left(\tau, \mu, e_{H}\right)>\mathbf{V}\left(\hat{\tau}\left(e_{L}\right), \hat{\mu}\left(e_{L}\right), e_{H}\right)
$$

(otherwise $\left\{e_{H}, e_{L}\right\}$ can induce $\pi^{1}$ and get $b / 2$ instead of $b / 3$ ) and

$$
\mathbf{V}(\tau, \mu, u)>\mathbf{V}\left(\hat{\tau}\left(e_{L}\right), \hat{\mu}\left(e_{L}\right), u\right)
$$

(otherwise $\left\{u, e_{L}\right\}$ can induce $\pi^{2}$ and get $b / 2$ instead of $b / 3$ ).

Now, suppose that $(\tau, \mu) \notin P_{\left\{e_{H}, u\right\}}$. Then $\left\{e_{H}, u\right\}$ should induce $\pi^{4}$ in order to implement a policy in $P_{\left\{e_{H}, u\right\}}$, which all its members prefer to $(\tau, \mu)$ (Lemma 3 (iii)). This would also allow them to get $b / 2$ instead of $b / 3$.

- $j=11$

There is no EPS involving $\pi^{11}$ as the $e_{L}$-politician can induce $\pi^{5}$, thus implementing her ideal policy and getting $b>b / 3$ (Lemma 5 ).

- $j=12$

$\left(\mathbf{S}^{\mathbf{1 2}}\right)$ is a direct corollary of part (iv) in Lemma 3.

- $j=13$

Suppose party $\left\{e_{L}, u, c\right\}$ offers a policy $(\tau, \mu)$ in an EPS involving structure $\pi^{13}$. This implies that voters of type $e_{L}$ must prefer $(\tau, \mu)$ to $\left(\hat{\tau}\left(e_{H}\right), \hat{\mu}\left(e_{H}\right)\right)$ (otherwise party $\left\{e_{H}\right\}$ could win the election by offering her ideal policy). Since

$$
\left\{(\tau, \mu) \in P_{\left\{e_{L}, u\right\}}: \mathbf{V}\left(\tau, \mu, e_{L}\right)>\mathbf{V}\left(\hat{\tau}\left(e_{H}\right), \hat{\mu}\left(e_{H}\right), e_{L}\right)\right\} \subseteq \delta\left(\pi^{2}\right),
$$

it is profitable for $\left\{e_{L}, u\right\}$ to induce $\pi^{2}$. Doing so, it can implement a policy that makes its members at least as well-off than $(\tau, \mu)$ and increase their non-policy benefit by $b / 2-b / 3>0$. This proves that there is no EPS involving $\pi^{13}$.

- $j=14$

Let $(\tilde{\tau}, \tilde{\mu}) \in \delta\left(\pi^{14}\right)$, and assume that $(\tilde{\tau}, \tilde{\mu}) \notin P_{\left\{e_{H}, u\right\}}=P_{\left\{e_{H}, e_{L}, u\right\}} \cap P_{\left\{e_{H}, u, c\right\}}$. This implies that either $(\tilde{\tau}, \tilde{\mu}) \in P_{\left\{e_{H}, e_{L}, u\right\}} \backslash P_{\left\{e_{H}, u\right\}}$ or $(\tilde{\tau}, \tilde{\mu}) \in P_{\left\{e_{H}, u, c\right\}} \backslash P_{\left\{e_{H}, u\right\}}$.

If $(\tilde{\tau}, \tilde{\mu}) \in P_{\left\{e_{H}, e_{L}, u\right\}} \backslash P_{\left\{e_{H}, u\right\}}$, then coalition $\left\{e_{H}, u, c\right\}$ can profitably induce $\pi^{12}$. This indeed allows its members to implement a policy they all prefer to $(\tilde{\tau}, \tilde{\mu})$ and to raise their non-policy benefit by $b / 3-b / 4$. If $(\tilde{\tau}, \tilde{\mu}) \in P_{\left\{e_{H}, u, c\right\}} \backslash P_{\left\{e_{H}, u\right\}}$, then coalition $\left\{e_{H}, e_{L}, u\right\}$ can similarly raise its members' payoffs by inducing $\pi^{10}$. Thus, $(\tilde{\tau}, \tilde{\mu})$ must belong to $P_{\left\{e_{H}, u\right\}}$ for $\left(\pi^{14},(\tilde{\tau}, \tilde{\mu})\right)$ to be an EPS. 
Now suppose $(\tilde{\tau}, \tilde{\mu}) \in P_{\left\{e_{H}, u\right\}}$ but

$$
\mathbf{V}(\tilde{\tau}, \tilde{\mu}, u)<\mathbf{V}\left(\hat{\tau}\left(e_{L}\right), \hat{\mu}\left(e_{L}\right), u\right) .
$$

Coalition $\left\{e_{L}, u\right\}$ can then profitably induce $\pi^{8}$. Enforcing $\left(\hat{\tau}\left(e_{L}\right), \hat{\mu}\left(e_{L}\right)\right)$, it can thus raise its members' policy and non-policy benefits.

Finally, coalition $\left\{e_{H}, e_{L}\right\}$ can similarly induce $\pi^{7}$ if $(\tilde{\tau}, \tilde{\mu}) \in P_{\left\{e_{H}, u\right\}}$ but

$$
\mathbf{V}\left(\tilde{\tau}, \tilde{\mu}, e_{H}\right)<\mathbf{V}\left(\hat{\tau}\left(e_{L}\right), \hat{\mu}\left(e_{L}\right), e_{H}\right),
$$

thus raising its members' policy and non-policy benefits.

\section{Appendix 6: Necessary conditions for conditions C1- C3 to hold}

Result 1 For any parametric configuration of the model, there exists $\bar{x}_{H} \in\left(x_{L}, 1\right)$ and $\bar{\pi}_{1} \in(0,1)$ such that, ceteris paribus:

(i) Conditions C1 and C2 hold if $x_{H} \in\left(\bar{x}_{H}, 1\right)$; and

(ii) condition C3 holds if $\pi(1) \in\left(\bar{\pi}_{1}, 1\right)$.

Proof: (i) Condition $\mathrm{C} 1$ holds if and only if the indifference curve of the $e_{H}$ politician passing through $\left(\hat{\tau}\left(e_{L}\right), \hat{\mu}\left(e_{L}\right)\right)$ is steeper (in the $(\tau, \mu)$ space) than the indifference curve of the $u$-politician passing through $\left(\hat{\tau}\left(e_{L}\right), \hat{\mu}\left(e_{L}\right)\right)$ (see Figure 1). Simple computations reveal that the slopes of the $e_{H^{-}}$and $u$-politicians' indifference 
curves passing through $\left(\hat{\tau}\left(e_{L}\right), \hat{\mu}\left(e_{L}\right)\right)$ are, respectively,

$$
\begin{aligned}
& S_{H}^{L}\left(x_{H}\right) \equiv\{\left(1-x_{H}\right) \underbrace{\pi^{\prime}(1)\left[U\left(\rho w_{c}-\hat{\tau}\left(e_{L}\right)\right)-U\left(\hat{\tau}\left(e_{L}\right) \frac{\ell+\kappa}{1-\ell}\right)\right]}_{>0}\}^{-1} \\
& \times\{\left[x_{H}+\left(1-x_{H}\right) \pi(1)\right] \underbrace{U^{\prime}\left(\rho w_{c}-\hat{\tau}\left(e_{L}\right)\right)}_{>0}-\left[1-x_{H}-\left(1-x_{H}\right) \pi(1)\right] \underbrace{\frac{\ell+\kappa}{1-\ell} U^{\prime}\left(\hat{\tau}\left(e_{L}\right) \frac{\ell+\kappa}{1-\ell}\right)}_{>0}\},
\end{aligned}
$$

and

$$
\begin{aligned}
& S_{u}^{L}\left(x_{H}\right) \equiv\{(1-x) \underbrace{\pi^{\prime}(1) \frac{\ell}{1-\ell}\left[U\left(\rho \hat{\tau}\left(e_{L}\right) \frac{1+\kappa}{1-\ell}-\hat{\tau}\left(e_{L}\right)\right)-U\left(\hat{\tau}\left(e_{L}\right) \frac{\ell+\kappa}{1-\ell}\right)\right]}_{>0}\}^{-1} \\
& \times\left\{(1-x)[1-\pi(1)] \frac{\ell}{1-\ell}\left(\rho \frac{1+\kappa}{1-\ell}-1\right) U^{\prime}\left(\rho \hat{\tau}\left(e_{L}\right) \frac{1+\kappa}{1-\ell}-\hat{\tau}\left(e_{L}\right)\right)\right. \\
& \left.+\left[1-\frac{(1-x)[1-\pi(1)] \ell}{1-\ell}\right] \frac{\ell+\kappa}{1-\ell} U^{\prime}\left(\hat{\tau}\left(e_{L}\right) \frac{\ell+\kappa}{1-\ell}\right)\right\} .
\end{aligned}
$$

Hence,

$$
0<\lim _{x_{H} \rightarrow 1} S_{u}^{L}\left(x_{H}\right)<\infty=\lim _{x_{H} \rightarrow 1} S_{H}^{L}\left(x_{H}\right) .
$$

By continuity, therefore, there must exist $\bar{x}_{1}<1$ such that $\mathrm{C} 1$ holds whenever $x_{H} \in\left(\bar{x}_{1}, 1\right)$.

For condition $\mathrm{C} 2$ to hold, type- $u$ citizens must strictly prefer $\left(\hat{\tau}\left(e_{L}\right), \hat{\mu}\left(e_{L}\right)\right)$ to any policy in the Pareto set of coalition $\left\{e_{H}, c\right\}$. As $x_{H}$ becomes arbitrarily close to 1 , this Pareto set becomes arbitrarily close to $\{(\tau, \mu) \in P: \tau=0\}\left(\tau\left(e_{H}\right)\right.$ tends to $0)$. As the utility of type- $u$ citizens is zero at any policy in $\{(\tau, \mu) \in P: \tau=0\}$ and $\hat{\tau}\left(e_{L}\right)>0$, we have

$$
\lim _{x_{H} \rightarrow 1} \mathbf{V}\left(\hat{\tau}\left(e_{L}\right), \hat{\mu}\left(e_{L}\right), u\right)>0>\mathbf{V}(\tau, \mu, u)
$$

for all $(\tau, \mu) \in\{(\tau, \mu) \in P: \tau=0\}$. By continuity, there consequently exists $\bar{x}_{2}<1$ such that C1 holds whenever $x_{H} \in\left(\bar{x}_{2}, 1\right)$. Hence, we obtain part (i) of Result 1 by setting $\bar{\pi}_{H} \equiv \max \left\{x_{L}, \bar{x}_{1}, \bar{x}_{2}\right\}$.

(ii) As $\pi(1)$ becomes arbitrarily close to unity, the ideal policy of type- $e_{L}$ citizens becomes arbitrarily close to $\left(\hat{\tau}\left(e_{H}\right), \hat{\mu}\left(e_{H}\right)\right)$. Then,

$$
\lim _{\pi(1) \rightarrow 1} \mathbf{V}\left(\hat{\tau}\left(e_{H}\right), \hat{\mu}\left(e_{H}\right), e_{L}\right)=\lim _{\pi(1) \rightarrow 1} \mathbf{V}\left(\hat{\tau}\left(e_{L}\right), \hat{\mu}\left(e_{L}\right), e_{L}\right)>\mathbf{V}\left(\tau, 0, e_{L}\right)
$$

for all $\tau \in[0,1]$. As above, we obtain the result by continuity. 


\section{Appendix 7: EPS if C2 or C3 does not hold.}

We contend in the text that conditions $\mathrm{C} 1$ to $\mathrm{C} 3$ are very reasonable, because sufficient conditions on $x_{H}$ and $\pi(1)$ for $\mathrm{C} 1$ to $\mathrm{C} 3$ to hold are either innocuous or empirically relevant. More precisely, condition C3 holds if $\pi(1)$ is large enough, which is an innocuous assumption since it only requires to allow for policies that would nearly prevent any firm from firing workers (for instance, by making it illegal or extremely expensive, except in very specific circumstances). We already know that $\mathrm{C} 1$ is both necessary and sufficient to have EPS exhibiting a negative correlation between UB and EPL. Observe that $\mathrm{C} 1$ holds if $x_{H}$ is sufficiently large, which is also a sufficient condition for $\mathrm{C} 2$ to hold (although the threshold values of $x_{H}$ above which conditions $\mathrm{C} 1$ and $\mathrm{C} 2$ hold are different). Moreover, empirical evidence strongly suggests that $x_{H}$ is indeed large.

One may nevertheless wonder what types of additional EPS may exist if conditions $\mathrm{C} 2$ and $\mathrm{C} 3$ are not satisfied (while $\mathrm{C} 1$ holds). Recall that conditions $\mathrm{C} 2$ and C3 are only sufficient to rule out policy outcomes outside the Pareto set of ability workers and unemployed. The next result describes what EPSs - other than those described in Proposition 3 - could exist when C1 holds but $\mathrm{C} 2$ and $\mathrm{C} 3$ do not.

Result 2 Suppose C1 holds. If $(\pi, \mathbf{p})$ is an EPS such that $\delta(\pi) \nsubseteq P_{\left\{e_{H}, u\right\}}$, then one of the following statements is true:

(i) C2 does not hold, $\pi=\left\{\left\{e_{H}, c\right\},\left\{e_{L}\right\},\{u\}\right\}$, and

$$
\delta(\pi) \subseteq\left\{\left(\tau^{\prime}, \mu^{\prime}\right) \in P_{\left\{e_{H}, c\right\}}: \mathbf{V}\left(\tau^{\prime}, \mu^{\prime}, \theta\right) \geq \mathbf{V}\left(\hat{\tau}\left(e_{L}\right), \hat{\mu}\left(e_{L}\right), \theta\right), \forall \theta \in\left\{e_{H}, u\right\}\right\}
$$

(ii) C3 does not hold, $\pi=\left\{\left\{e_{H}\right\},\left\{e_{L}\right\},\{u, c\}\right\}$, and

$$
\delta(\pi) \subseteq\left\{\left(\tau^{\prime}, 0\right) \in P_{\{u, c\}}: \mathbf{V}\left(\tau^{\prime}, 0, e_{j}\right) \geq \mathbf{V}\left(\hat{\tau}\left(e_{k}\right), 1, e_{j}\right), \forall j, k \in\{L, H\}, j \neq k\right\}
$$

Proof of Result 2: Let $(\pi, \mathbf{p})$ be an EPS such that $\delta(\pi) \nsubseteq P_{\left\{e_{H}, u\right\}}$, and let $(\tau, \mu) \in \delta(\pi)$. Note that, as $\mathrm{C} 1$ holds, Lemma 3 applies. We can thus use the same reasoning as in the proof of Proposition 3 to show that $\pi \notin\left\{\pi^{j}: j=\right.$ $0,1,2,3,4,7,9,10,12,13,14\}$.

Suppose $\pi=\pi^{5}$. By the same logic as in the proof of Proposition 3, there are only three possible types of $\pi^{5}$-equilibria: (1) $\left\{e_{L}\right\}$ runs alone; (2) there is a tie between 
$\left\{e_{H}, c\right\}$ and $\left\{e_{L}\right\}$; and (3) $\left\{e_{H}, c\right\}$ runs unopposed and, therefore, $(\tau, \mu) \in P_{\left\{e_{H}, c\right\}}$. We already know that case (1) cannot be an EPS (Lemma 3 (iii) and condition C1). Case (2) implies that voters of type $u$ are indifferent between $\left(\hat{\tau}\left(e_{L}\right), \hat{\mu}\left(e_{L}\right)\right)$ and the policy $\left(\tau^{\prime}, \mu^{\prime}\right)$ offered by $\left\{e_{H}, c\right\}$. But this cannot be a $\pi^{5}$-equilibrium: By continuity of payoff functions, there exists $\left(\tau^{\prime \prime}, \mu^{\prime \prime}\right) \in P_{\left\{e_{H}, c\right\}}$ in an $\varepsilon$-neighborhood of $\left(\tau^{\prime}, \mu^{\prime}\right)$, with $\varepsilon>0$ arbitrarily small, such that all members of $\left\{e_{H}, u, c\right\}$ strictly prefer $\left(\tau^{\prime \prime}, \mu^{\prime \prime}\right)$ to $\left(\hat{\tau}\left(e_{L}\right), \hat{\mu}\left(e_{L}\right)\right)$. A deviation to $\left(\tau^{\prime \prime}, \mu^{\prime \prime}\right)$ is therefore strictly profitable to party $\left\{e_{H}, c\right\}$ : the party wins for sure and any arbitrarily small utility loss ( $\varepsilon$ is arbitrarily small) is compensated by the increase in non-utility benefits $(b / 2)-(b / 4)>0$. For case $(3)$ to constitute an EPS, $\{(\tau, \mu), \varnothing, \varnothing\}$ has to be a $\pi^{5}$-equilibrium. That is, $\left\{e_{L}\right\}$ must not have a profitable deviation; this requires the following condition to be true:

$$
\mathbf{V}(\tau, \mu, \theta) \geq \mathbf{V}\left(\hat{\tau}\left(e_{L}\right), \hat{\mu}\left(e_{L}\right), \theta\right), \forall \theta \in\left\{e_{H}, u\right\}
$$

Hence, C2 does not hold.

Suppose now that $\pi=\pi^{6}$. By the same logic as in the proof of Proposition 3 , there are only two possible types of EPSs with $\pi^{6}$ : (1) there is a tie between $\{u, c\}$ and $\left\{e_{H}\right\}$; and (2) $\{u, c\}$ runs alone and, therefore, $(\tau, \mu) \in P_{\{u, c\}}$. Case (1) requires voters of type $e_{L}$ to be indifferent between the policies offered by $\{u, c\}$ and $\left\{e_{H}\right\}$, and therefore that $\lambda \ell=1-\ell+\kappa$. As $\lambda<1 / 2$, we must then have $(1-\lambda) \ell>\lambda \ell=1-\ell+\kappa$. This in turn implies that $\left\{e_{L}\right\}$ can profitably deviate: it wins with probability 1 if it runs and offers its ideal policy. For case (2) to constitute an EPS, $\{\varnothing, \varnothing,(\tau, \mu)\}$ has to be a $\pi^{6}$-equilibrium. That is, neither $\left\{e_{L}\right\}$ nor $\left\{e_{H}\right\}$ can profitably deviate; this requires the following condition to be true:

$$
\mathbf{V}\left(\tau, 0, e_{j}\right) \geq \mathbf{V}\left(\hat{\tau}\left(e_{k}\right), 1, e_{j}\right), \forall j, k \in\{L, H\}, j \neq k .
$$

Hence, C3 does not hold.

If $\pi=\pi^{8}$, then party $\left\{e_{L}, u\right\}$ must win for sure (recall that $\left\{e_{L}, u\right\}$ constitutes a majority coalition), so that $(\tau, \mu) \in P_{\left\{e_{L}, u\right\}}$. Furthermore, $(\tau, \mu)$ must be equal to $\left(\hat{\tau}\left(e_{L}\right), \hat{\mu}\left(e_{L}\right)\right)$; otherwise the $e_{H}$-politician can profitably induce $\pi^{2}$. Indeed $\left(\hat{\tau}\left(e_{L}\right), \hat{\mu}\left(e_{L}\right)\right) \in \delta\left(\pi^{2}\right)$ - recall that $u$ strictly prefers $\left(\hat{\tau}\left(e_{L}\right), \hat{\mu}\left(e_{L}\right)\right)$ to both $\left(\hat{\tau}\left(e_{H}\right), \hat{\mu}\left(e_{H}\right)\right)$ and $(\hat{\tau}(c), \hat{\mu}(c))$ - and $\left(\hat{\tau}\left(e_{L}\right), \hat{\mu}\left(e_{L}\right)\right)$ is the $e_{H}$-politician's mostpreferred policy in $P_{\left\{e_{L}, u\right\}}$.

If $\delta\left(\pi^{5}\right)=\left\{\left(\hat{\tau}\left(e_{L}\right), \hat{\mu}\left(e_{L}\right)\right)\right\}$, then the $e_{L}$-politician can profitably induce $\pi^{5}$ from $\pi^{8}$ : Doing so, she can indeed enforce her ideal policy and receive the entire benefit $b$. If $\delta\left(\pi^{5}\right) \neq\left\{\left(\hat{\tau}\left(e_{L}\right), \hat{\mu}\left(e_{L}\right)\right)\right\}$, then party $\left\{e_{H}, c\right\}$ can win with a positive probability when pitted against $\left\{e_{L}\right\}$ in party structure $\pi^{5}$. This implies that some $\left(\tau_{1}, \mu_{1}\right) \in P_{\left\{e_{H}, c\right\}}$ must satisfy (12) with a strict inequality for at least one element of $\left\{e_{H}, u\right\}$. By continuity, this in turn implies that there exists some $\left(\tau_{2}, \mu_{2}\right) \in P_{\left\{e_{H}, c\right\}}$ in an arbitrarily small neighborhood of $\left(\tau_{1}, \mu_{1}\right)$ such that

$$
\mathbf{V}\left(\tau_{2}, \mu_{2}, \theta\right)>\mathbf{V}\left(\hat{\tau}\left(e_{L}\right), \hat{\mu}\left(e_{L}\right), \theta\right), \forall \theta \in\left\{e_{H}, u, c\right\} .
$$


Hence, $\delta\left(\pi^{5}\right)$ comprises policies in $P_{\left\{e_{H}, c\right\}}$ that are strictly preferred to $\left(\hat{\tau}\left(e_{L}\right), \hat{\mu}\left(e_{L}\right)\right)$ by all members of $\left\{e_{H}, u, c\right\}$. This implies that, in party structure $\pi^{8}$, party $\left\{e_{H}, c\right\}$ can profitably deviate by offering such a policy when party $\left\{e_{L}, u\right\}$ offers $\left(\hat{\tau}\left(e_{L}\right), \hat{\mu}\left(e_{L}\right)\right)$. This proves that there is no EPS involving $\pi^{8}$; a contradiction with $\pi=\pi^{8}$.

If $\pi=\pi^{11}$, party $\left\{e_{H}, e_{L}, c\right\}$ must win for sure by offering $(\tau, \mu) \in P_{\left\{e_{H}, e_{L}, c\right\}}$. This implies that voters of type $e_{L}$ (weakly) prefer $(\tau, \mu)$ to $(\hat{\tau}(u), \hat{\mu}(u))$; otherwise $\{u\}$ could profitably deviate by offering its ideal policy. Hence:

$$
(\tau, \mu) \in P_{0} \equiv\left\{\left(\tau^{\prime}, \mu^{\prime}\right) \in P_{\left\{e_{H}, e_{L}, c\right\}}: \mathbf{V}\left(\tau^{\prime}, \mu^{\prime}, e_{L}\right) \geq \mathbf{V}\left(\hat{\tau}(u), \hat{\mu}(u), e_{L}\right)\right\}
$$

Now, let

$$
\begin{aligned}
& P_{1} \equiv\left\{\left(\tau^{\prime}, \mu^{\prime}\right) \in P_{0}: \mathbf{V}\left(\tau^{\prime}, \mu^{\prime}, e_{L}\right)>\mathbf{V}\left(\hat{\tau}\left(e_{H}\right), \hat{\mu}\left(e_{H}\right), e_{L}\right)\right\} \\
& P_{2} \equiv\left\{\left(\tau^{\prime}, \mu^{\prime}\right) \in P_{0}: \mathbf{V}\left(\tau^{\prime}, \mu^{\prime}, e_{L}\right) \leq \mathbf{V}\left(\hat{\tau}\left(e_{H}\right), \hat{\mu}\left(e_{H}\right), e_{L}\right)\right\}
\end{aligned}
$$

Thus, either $(\tau, \mu) \in P_{1}$ or $(\tau, \mu) \in P_{2}$. In the former case, there exists a policy in

$$
P_{4} \equiv\left\{\left(\tau^{\prime}, \mu^{\prime}\right) \in P_{\left\{e_{L}, c\right\}} \cap P_{1}: \mathbf{V}\left(\tau^{\prime}, \mu^{\prime}, e_{L}\right)>\mathbf{V}\left(\hat{\tau}\left(e_{H}\right), \hat{\mu}\left(e_{H}\right), e_{L}\right)\right\}
$$

that is preferred to $(\tau, \mu)$ by all members of $\left\{e_{L}, c\right\}$. It is readily checked that by construction $P_{4} \subseteq \delta\left(\pi^{3}\right)$ : any element of $P_{4}$ is strictly preferred by $u$ and $e_{L}$ to $\left(\hat{\tau}\left(e_{H}\right), \hat{\mu}\left(e_{H}\right)\right)$, and strictly preferred by $e_{H}$ and $e_{L}$ to $(\hat{\tau}(u), \hat{\mu}(u))$. Coalition $\left\{e_{L}, c\right\}$ can therefore profitably induce $\pi^{3}$. If $(\tau, \mu) \in P_{2}$, then $\mathbf{V}\left(\hat{\tau}\left(e_{H}\right), \hat{\mu}\left(e_{H}\right), e_{L}\right) \geq$ $\mathbf{V}\left(\hat{\tau}(u), \hat{\mu}(u), e_{L}\right)$ (otherwise $\left.P_{2}=\emptyset\right)$. This implies that $P_{\left\{e_{H}, e_{L}\right\}} \backslash\left\{\left(\hat{\tau}\left(e_{H}\right), \hat{\mu}\left(e_{H}\right)\right)\right\}$ is a subset of $\delta\left(\pi^{1}\right)$ : By construction, any element of $P_{\left\{e_{H}, e_{L}\right\}} \backslash\left\{\left(\hat{\tau}\left(e_{H}\right), \hat{\mu}\left(e_{H}\right)\right)\right\}$ is strictly preferred by $u$ and $e_{L}$ to $(\hat{\tau}(c), \hat{\mu}(c))$, and strictly preferred by $e_{H}$ and $e_{L}$ to $(\hat{\tau}(u), \hat{\mu}(u))$. By definition of a Pareto set, there consequently exists a policy $\left(\tau^{\prime}, \mu^{\prime}\right) \in P_{\left\{e_{H}, e_{L}\right\}}$ (which may coincide with $(\tau, \mu)$ ) such that coalition $\left\{e_{H}, e_{L}\right\}$ can profitably induce $\pi^{1}$ and enforce $\left(\tau^{\prime}, \mu^{\prime}\right)$. Doing so, it guarantees its members at least the same utility from policy, and increases their non-utility benefits by $(b / 2)-(b / 3)=b / 6>0$. This proves that there is no EPS involving party structure $\pi^{11}$, and thus ends the proof of Result 2 .

First, observe that, even though we describe in Result 2 the characteristics of all the EPSs that may appear when either C2 or C3 is not satisfied (while C1 holds), we do not provide necessary conditions that would guarantee the existence of such EPSs. Doing so would require to introduce other conditions on, for instance, the functions $U($.$) and \pi($.$) , and to develop even lengthier proofs.$

The two types of potential EPS are quite intuitive. If $\mathrm{C} 2$ does not hold, then a coalition of capitalists and high ability workers can propose some policy in their 
Pareto set that is favored by the unemployed to the most-preferred policy of the low ability workers. The coalition of $c$ and $e_{H}$ then wins the election with such a policy, since type $e_{L}$ can not obtain the support of the unemployed with its most-preferred policy. Observe that these potential equilibria are located on the upward-sloping Pareto set of types $e_{H}$ and $c$, so that we should observe a positive correlation between UB and EPL - the opposite of the empirical evidence. If C3 does not hold, meaning that $\pi(1)$ is low, then there is enough difference in the preferences of the two types of workers for the other two types of voters to take advantage of. Namely, capitalists and unemployed coalesce to propose some policy with zero EPL that both the lowand the high-ability workers prefer to the most-preferred policy of the other type of workers. Observe that most countries exhibit at least some level of EPL, which contradicts this type of EPS.

\section{References}

Anesi, V., De Donder, Ph., 2009. Party Formation and Minority Ideological Positions. The Economic Journal 119, 1303-1323.

Anesi V., De Donder, Ph., 2011. Secondary Issues and Party Politics. An Application to Environmental Policy. Social Choice and Welfare 36, 519-546.

Baron, D.P., Diermeier, D., Fong, P., forthcoming. A Dynamic Theory of Parliamentary Democracy. Economic Theory.

Belot, M., 2007. Why is the Employment Protection Stricter in Europe than in the US? Economica 74 (295), 397-423.

Besley, T., Coate, S., 1997. An Economic Model of Representative Democracy. Quarterly Journal Economics 108, 85-114.

Blanchard, O., Tirole, J., 2007. The Optimal Design of Unemployment Insurance and Employment Protection: A First Pass. Journal of the European Economic Association 6, 45-77.

Boeri, T., Burda, M., 2003. Preferences for Rigid versus Individualized Wage Setting in Search Economies with Firing Frictions. mimeo.

Boeri, T., Conde-Ruiz, J.I., Galasso, V., 2011. The Political Economy of Flexicurity. Journal of the European Economic Association, forthcoming.

Brügemann, B., 2003. Trade Integration and the Political Support for Labor Market Rigidity. mimeo, Yale University. 
Brügemann, B., 2006. Does Employment Protection Create Its Own Political Support? IZA Discussion Paper No. 2286.

Buti, M., Pench, L., Sestito, P., 1998. European Unemployment: contending theories and institutional complexities. Policy Paper 98/1, The Robert Schuman Centre, European University Institute.

Cahuc, P., Postel-Vinay, F., 2002. Temporary jobs, employment protection and labor market performance. Labour Economics 9, 63-91.

Chambers, C.P., 2007. Citizen-Candidates, Lobbies, and Strategic Campaigning. Economic Theory 33, 285-309.

Chung, Y.-K., Jeong, J., 2008. Analysis of Employment Protection Laws and Unemployment Benefits. Economics Letters 99, 144-146.

Dhillon, A., 2005. Political Parties and Coalition Formation, in "Group Formation in Economics; Networks, Clubs and Coalitions," eds G.Demange and M.Wooders, Cambridge University Press, 289-302.

Eguia, J.X., forthcoming. A Spatial Theory of Party Formation. Economic Theory.

Fernandez, R., Levy, G., 2008. Diversity and Redistribution. Journal of Public Economics 92 (5-6), 925-943.

Gomberg, A.M., Marhuenda, F., Ortuño-Ortín, I., 2004. A Model of Endogenous Political Party Platforms. Economic Theory 24, 373-394.

Hassler, J., Rodriguez Mora, 1999. Employment turnover and the public allocation of unemployment insurance. Journal of Public Economics 73, 55-83.

Hassler, J., Rodriguez Mora, V., Storesletten, K., Zilibotti, F., 2005. A Positive Theory of Geographic Mobility and Social Insurance. International Economic Review 46(1), 263-303.

Iaryczower, M., Mattozzi, A., forthcoming. The Pro-Competitive Effect of Campaign Limits in Non-Majoritarian Elections. Economic Theory.

Koeniger, W., Vindigni, A., 2003. Employment Protection and Product Market regulation. IZA Discussion paper 880 .

Lee, W., Roemer, J.E., 2005. The Rise and Fall of Unionised Labour Markets: A Political Economy Approach. Economic Journal 115, 28-67.

Levy, G., 2004. A Model of Political Parties. Journal of Economic Theory 115, 250-277. 
Levy, G., 2005. The Politics of Public Provision of Education. The Quarterly Journal of Economics 120(4), 1507-1534.

Mukoyama, T., Şahin, A., 2005. Repeated Moral Hazard with Persistence. Economic Theory 25, 831-854.

OECD, 1995. The OECD Jobs Study. Paris.

Osborne, M.J., Slivinski, A., 1996. A Model of Political Competition with CitizenCandidates. Quarterly Journal of Economics 111, 65-96.

Pagano, M., Volpin, P.F., 2005. The Political Economy of Corporate Governance. American Economic Review 95, 1005-1030.

Pallage, S., Zimmermann, C., 2001. Voting on Unemployment Insurance. International Economic Review 42, 903-923.

Persson,T., Tabellini, G., 2000. Political Economics. Explaining Economic Policy. MIT Press, Cambridge, Massachusetts, London, England.

Roemer, J.E., 2005. Will Democracy Engender Equality? Economic Theory 25, 217-234.

Rueda, D., 2006. Social Democracy and Active Labour-Market Policies, British Journal of Political Sciences 36, 385-406.

Saint-Paul, G., 1996. Exploring the Political Economy of Labor Market Institutions. Economic Policy 23, 265-315.

Saint-Paul, G., 1999. Assessing the Political Viability of Labor Market Reform: The Case of Employment Protection. CEPR Discussion Paper, No. 2136.

Saint-Paul, G., 2000. The Political Economy of Labor Market Institutions. Oxford University Press.

Saint-Paul, G., 2002. The Political Economy of Employment Protection. Journal of Political Economy 110, pp. 672-704.

Vindigni, A., 2008. Uncertainty and the politics of employment protection. IZA Discussion Paper No. 3509.

Wright, R., 1996. The Redistributive Role of Unemployment Insurance and the Dynamics of Voting. Journal of Public Economics 31, 377-399. 


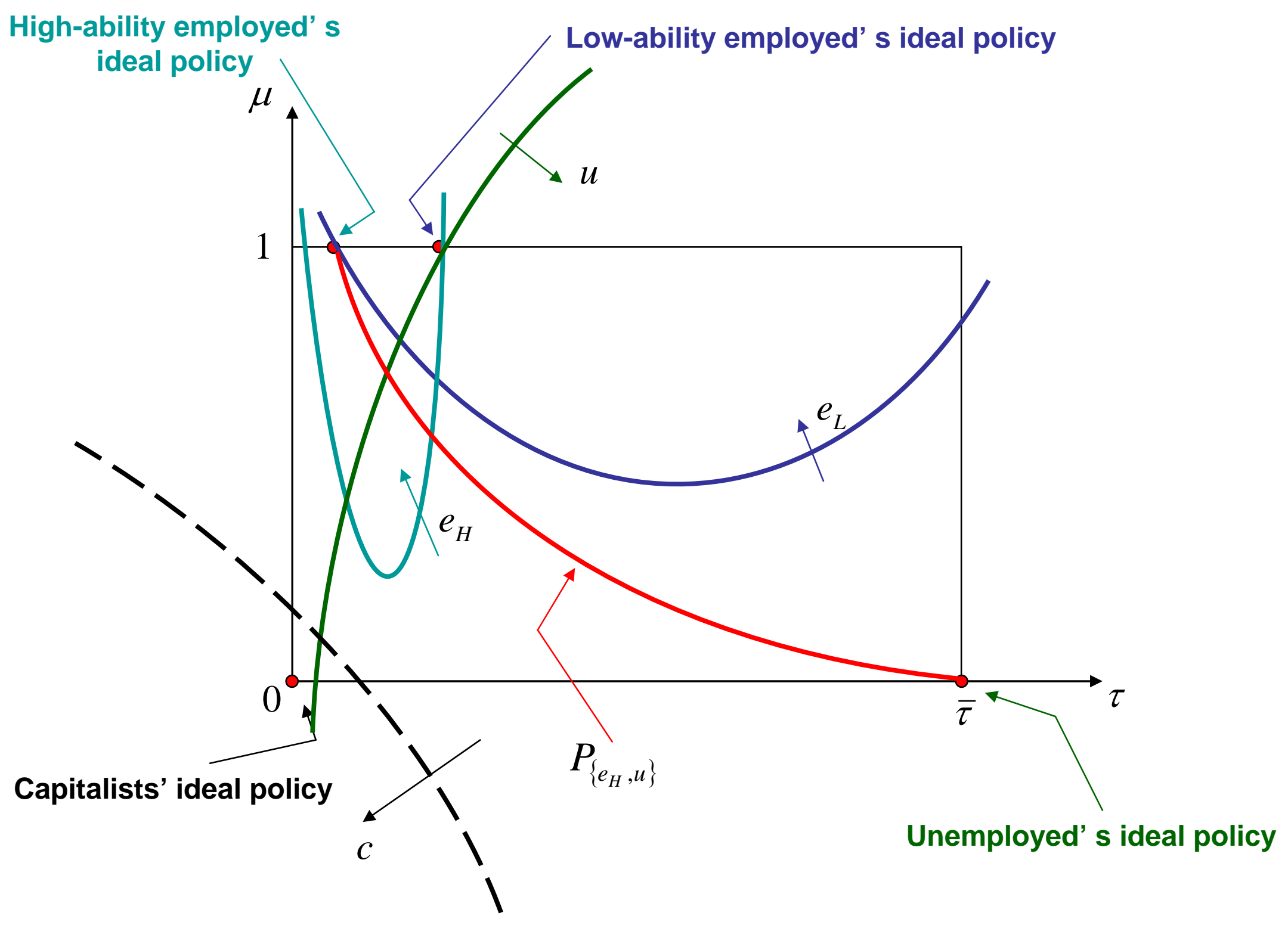

